\title{
Cholinergic Modulation of Stimulus-Specific Adaptation in the Inferior Colliculus
}

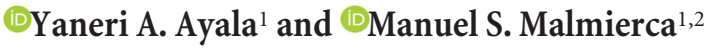 \\ ${ }^{1}$ Auditory Neuroscience Laboratory, Institute of Neuroscience of Castilla y León and 2Department of Cell Biology and Pathology, Faculty of Medicine, \\ University of Salamanca, 37007 Salamanca, Spain
}

Neural encoding of an ever-changing acoustic environment is a complex and demanding process that depends on modulation by neuroactive substances. Some neurons of the inferior colliculus (IC) exhibit "stimulus-specific adaptation" (SSA), i.e., a decrease in their response to a repetitive sound, but not to a rare one. Previous studies have demonstrated that acetylcholine (ACh) alters the frequency response areas of auditory neurons and therefore is important in the encoding of spectral information. Here, we address how microiontophoretic application of ACh modulates SSA in the IC of the anesthetized rat. We found that ACh decreased SSA in IC neurons by increasing the response to the repetitive tone. This effect was mainly mediated by muscarinic receptors. The strength of the cholinergic modulation depended on the baseline SSA level, exerting its greatest effect on neurons with intermediate SSA responses across IC subdivisions. Our data demonstrate that the increased availability of ACh exerts transient functional changes in partially adapting IC neurons, enhancing the sensory encoding of the ongoing stimulation. This effect potentially contributes to the propagation of ascending sensory-evoked afferent activity through the thalamus en route to the cortex.

Key words: acetylcholine; attention; auditory; microiontophoresis; neuromodulators; SSA

\section{Significance Statement}

Neural encoding of an ever-changing acoustic environment is a complex and demanding task that may depend on the available levels of neuroactive substances. We explored how the cholinergic inputs affect the responses of neurons in the auditory midbrain that exhibit different degrees of stimulus-specific adaptation (SSA), i.e., a specific decrease in their response to a repeated sound that does not generalize to other, rare sounds. This work addresses the role of cholinergic synaptic inputs as well as the contribution of the muscarinic and nicotinic receptors on SSA. This is the first report on the role of neuromodulation on SSA, and the results contribute to our understanding of the cellular bases for processing low- and high-probability sounds.

\section{Introduction}

Neural encoding of an ever-changing acoustic environment is a complex and demanding task that depend on modulation by neuroactive substances (Sarter et al., 2005; Harris and Thiele, 2011; Edeline, 2012; Froemke, 2015). Synapses activated during different

\footnotetext{
Received March 8, 2015; revised July 13, 2015; accepted July 28, 2015.

Author contributions: Y.A.A. and M.S.M. designed research; Y.A.A. performed research; Y.A.A. contributed unpublished reagents/analytic tools; Y.A.A. analyzed data; Y.A.A. and M.S.M. wrote the paper.

This work was supported by Ministerio de Economía y Competitividad Grants BFU201343608-P and PSI201349348-EXP and Junta de Castilla y León Grant SA343U14 to M.S.M., Y.A.A. held Consejo Nacional de Ciencia y Tecnologia Fellowship 216106 and a Secretaría de Educación Pública fellowship. We thank Drs. Nell Cant, Raju Metherate, and Adrian Rees for their comments on a previous version of this manuscript and for their constructive criticisms.

The authors declare no competing financial interests.

Correspondence should be addressed to Manuel S. Malmierca, Auditory Neuroscience Laboratory, Institute of Neuroscience of Castilla y León, University of Salamanca, Calle Pintor Fernando Gallego 1, 37007 Salamanca, Spain. E-mail:msm@usal.es.

DOI:10.1523/JNEUROSCI.0909-15.2015

Copyright $\odot 2015$ the authors $\quad 0270-6474 / 15 / 3512261-12 \$ 15.00 / 0$
}

modulatory states lead to plasticity changes that alter the global and fine-scale balance of excitation and inhibition (Froemke, 2015).

In the auditory brain, neurons that specifically decrease their response to a repeated sound but resume their firing when deviant stimuli are presented are found in the primary auditory cortex (AC; Ulanovsky et al., 2003; von der Behrens et al., 2009), auditory thalamus (Antunes et al., 2010), and inferior colliculus (IC; Pérez-González et al., 2005; Malmierca et al., 2009). This differential response to repeated versus rare sounds is referred to as "stimulus-specific adaptation" (SSA) and might reflect a special type of short-term plasticity that transiently modulates neural responsiveness in an activity-dependent manner (Jääskeläinen et al., 2007; Nelken, 2014). SSA may contribute to the upstream encoding of mismatch signals to repeated and deviant sounds observed at larger spatial and temporal scales in electroencephalographic studies (Nelken and Ulanovsky, 2007; Escera and Malmierca, 2014; Malmierca et al., 2014). In humans, the encoding of repeated and rare sounds is affected by top-down processing (Todorovic and de Lange, 2012) and by 
the application of modulatory substances, such as cholinergic compounds, that are known to vary across vigilance and cognitive states (Moran et al., 2013; Grupe et al., 2014; Knott et al., 2014).

It has been suggested that cholinergic modulation may shift brain activity from a discrimination mode to a detection mode, thus favoring the encoding of ongoing stimulation (Hasselmo and McGaughy, 2004; Sarter et al., 2005; Jääskeläinen et al., 2007). In the AC, ACh enhances responses to afferent sensory input while decreasing intracortical processing (Metherate and Ashe, 1993; Hsieh et al., 2000). Moreover, previous studies have demonstrated that cholinergic modulation alters frequency response areas of auditory neurons and therefore is important in the encoding of spectral representation (Ashe et al., 1989; Metherate and Weinberger, 1989, 1990; Ji et al., 2001; Ma and Suga, 2005).

The main goal of the present study was to determine what role, if any, ACh plays in generation or modulation of SSA. We used microiontophoretic application of ACh and antagonists for nicotinic and muscarinic receptors to address how ACh affects the responses of IC neurons that exhibit SSA. Preliminary reports have been presented previously (Ayala and Malmierca, 2014, 2015).

\section{Materials and Methods}

Subjects and surgical procedures. Experiments were performed on 44 adult female rats (Rattus norvegicus; Long-Evans) with body weights ranging from 180 to $333 \mathrm{~g}$. All surgical, recording, and histological procedures were conducted at the University of Salamanca, Spain. The experimental protocols were approved by Animal Care Committees of the University of Salamanca and followed the standards of the European Union (Directive 2010/63/EU) for the use of animals in neuroscience research. Detailed procedures were given previously (Malmierca et al., 2003, 2005, 2009; Hernandez et al., 2005). Anesthesia was induced using a mixture of ketamine chlorohydrate (30 mg/kg, i.m.; Imalgene 1000, Rhone Méreuse) and xylazine chlorohydrate ( $5 \mathrm{mg} / \mathrm{kg}$; Rompun, Bayer). Body temperature was monitored with a rectal probe and maintained at $38 \pm$ $1^{\circ} \mathrm{C}$ with a thermostatically controlled electric blanket. The trachea was cannulated, and atropine sulfate $(0.05 \mathrm{mg} / \mathrm{kg}$, s.c.; Braun $)$ was administered to reduce bronchial secretions. The animals were connected to a ventilator (SAR-830/P; CWE Inc.), and expired $\mathrm{CO}_{2}$ was monitored using a capnograph (Capstar-100; CWE Inc.). A craniotomy was performed on the left and right parietal bones, exposing the cerebral cortex, to gain access to the IC. To perform electrophysiological recordings from IC neurons, anesthesia was maintained with an initial intraperitoneal injection of urethane $(750 \mathrm{mg} / \mathrm{kg}$, Sigma-Aldrich) and with booster doses of one-third of the initial amount.

Acoustic delivery and electrophysiological recording. Before surgery, auditory brainstem responses (ABRs) to clicks $(100 \mu \mathrm{s}, 10 \mathrm{~Hz}$ rate) delivered in $10 \mathrm{~dB}$ SPL ascending steps from 10 to $90 \mathrm{~dB}$ SPL were obtained to check that the animal had normal hearing with thresholds lower than or equal to $30 \mathrm{~dB}$ SPL. ABR recordings were performed inside a soundattenuated room, using a closed-field sound delivery system and a realtime signal processing system (System 3, Tucker-Davis Technologies). Subcutaneous needle electrodes placed at the vertex (active electrode), the mastoid ipsilateral to the stimulated ear (reference electrode), and the mastoid contralateral to the stimulated ear (ground electrode) were used for the recordings. Evoked potentials were averaged from 500 presentations, and the final signal was filtered with a $300 \mathrm{~Hz}$ high-pass filter and a $3000 \mathrm{~Hz}$ low-pass filter, with hearing thresholds determined visually. Afterward, the animal was placed in a stereotaxic frame in which the ear bars were replaced by a hollow speculum that accommodated a sound delivery system (Rees, 1990) using two electrostatic loudspeakers (EC1, Tucker-Davis Technologies). Search stimuli were pure tones or white noise driven by a Tucker-Davis Technologies System 2 that was controlled by custom software for stimulus generation and on-line data visualization (Faure et al., 2003; Pérez-González et al., 2005, 2006; Malmierca et al., 2008). Action potentials were recorded with a Tucker-Davis Technologies BioAmp amplifier, the $10 \times$ output of which was further amplified and bandpass filtered (PC1, Tucker-Davis Technologies; frequency cut, $0.5-3 \mathrm{kHz}$ ) before passing through a spike discriminator (SD1, Tucker-Davis Technologies). Spike times were logged at $1 \mu \mathrm{s}$ resolution on a computer by feeding the output of the spike discriminator into an event timer (ET1, Tucker-Davis Technologies) synchronized to a timing generator (TG6, Tucker-Davis Technologies). Extracellular single-unit responses were recorded in the left and/or right IC of each animal to contralateral stimulation. The IC was approached from $20^{\circ}$ relative to the frontal plane so that the recording electrode moved caudal and ventral during the penetration. The electrode was lowered into the brain with a piezoelectric microdrive (Burleigh 6000 ULN) mounted on a stereotaxic manipulator to a depth of $3.5-5 \mathrm{~mm}$, where acoustically driven responses were found. After a neuron was isolated, pure tone stimuli with a duration of $75 \mathrm{~ms}$ ( $5 \mathrm{~ms}$ rise/fall time) were delivered to obtain the monaural frequency response area (FRA), i.e., the combination of frequencies and intensities capable of evoking a suprathreshold response. Five stimulus repetitions at each frequency (from 0.5 to 40 $\mathrm{kHz}$, in 20-25 logarithmic steps) and intensity step (steps of $10 \mathrm{~dB}$, from 0 to $80 \mathrm{~dB}$ SPL) were presented randomly at a repetition rate of $4 \mathrm{~Hz}$.

Stimulus presentation paradigm. Pure tones ( $75 \mathrm{~ms}, 5 \mathrm{~ms}$ rise/fall time) were presented in an oddball paradigm similar to that used to record mismatch negativity responses in human studies (Näätänen, 1992) and more recently in animal studies of SSA (Ulanovsky et al., 2003, 2004). Briefly, this paradigm consists of a flip-flop design using two pure tones at two different frequencies ( $f 1$ and $f 2$ ), both of which elicited similar firing rates and response patterns at a level of 10-40 dB SPL above threshold within the neural FRA. For most of the neurons (64\%), the $f 1$ and $f 2$ tones were located around the characteristic frequency (CF; the sound frequency that produces a response at the lowest stimulus level), whereas the rest of the frequency pairs were both either lower $(23 \%)$ or higher $(13 \%)$ than the CF. The frequency separations between $f 1$ and $f 2$ varied between 0.14 octaves and 0.53 octaves. A train of 300 or 400 stimulus presentations containing both frequencies was delivered in two different sequences (sequences 1 and 2). The repetition rate of the train of stimuli was $4 \mathrm{~Hz}$, as this was demonstrated previously to elicit SSA in IC neurons of the rat (Malmierca et al., 2009; Ayala et al., 2013). In sequence 1 , the $f 1$ frequency was presented as the standard tone with a high probability of occurrence ( $90 \%)$ within the sequence. Interspersed randomly among the standard stimuli were the $f 2$ frequency-deviant stimuli $(10 \%$ probability). After the sequence 1 data set was obtained, the relative probabilities of the two stimuli were reversed, with $f 2$ as the standard and $f 1$ as the deviant in sequence 2 .

Electrodes and iontophoresis. A tungsten electrode (1-2.5 M 2 ; Merrill and Ainsworth, 1972) was used to record single-neuron activity. It was attached to a multibarrel borosilicate glass pipette that carried drugs to be delivered in the vicinity of the recorded neuron. The tip of the recording electrode protruded $15-25 \mu \mathrm{m}$ from the pipette tip. The glass pipette consisted of five barrels in an $\mathrm{H}$ configuration (World Precision Instruments, catalog no. 5B120F-4) with the tip broken to a diameter of $20-30 \mu \mathrm{m}$. The center barrel was filled with saline for current compensation ( $165 \mathrm{~mm} \mathrm{NaCl})$, whereas the others were filled with 1 м ACh chloride (Sigma, catalog no. A6625), 0.5 m scopolamine hydrobromide (Sigma, catalog no. S0929), or 0.5 м mecamylamine hydrochloride (Tocris Bioscience, catalog no. 2843). The drugs were dissolved in distilled water and their $\mathrm{pH}$ adjusted to 4-4.2. ACh chloride acts at both muscarinic and nicotinic receptors, whereas the scopolamine and mecamylamine are nonselective antagonists of muscarinic and nicotinic receptors, respectively. These compounds have been used previously in the mammalian IC (Farley et al., 1983; Habbicht and Vater, 1996). The drugs were retained in the pipette with a $-15 \mathrm{nA}$ current and were ejected, when required, typically using 30-40 nA currents (Neurophore BH-2 system, Harvard Apparatus). The duration of the drug ejection usually lasted 15-25 min, but could be extended when no visual effect was observed to ensure the absence of effect. After the drug ejection, we repeated the stimulation protocol until we observed recovery of firing. 
Verification of the recording sites. Once the electrophysiological recordings were completed, electrolytic lesions (10-20 $\mu \mathrm{A}$ for $15 \mathrm{~s})$ were applied for subsequent histological verification of the recording sites in 24 of the 44 animals. Brains were fixed using a mixture of $1 \%$ paraformaldehyde and $1 \%$ glutaraldehyde diluted in $0.4 \mathrm{M} \mathrm{PBS}\left(0.5 \% \mathrm{NaNO}_{3}\right.$ in PBS). After fixation, tissue was cryoprotected in $30 \%$ sucrose and sectioned in the coronal or sagittal plane at a thickness of $50 \mu \mathrm{m}$ on a freezing microtome. Slices were stained with $0.1 \%$ cresyl violet to facilitate identification of cytoarchitectural boundaries. The recorded units were assigned to one of the four main subdivisions of the IC [the rostral (RCIC), lateral (LCIC), or dorsal cortex of the IC (DCIC) or the central nucleus of the IC (CNIC); Loftus et al., 2008; Malmierca et al., 2011; Ayala et al., 2015], using as reference the standard sections from a rat brain atlas (Paxinos and Watson, 2007).

Analysis of neural responses. For each neuron, the total raw number of spikes in response to the standard and deviant stimuli were normalized to the total number of deviant and standard trials, to account for the different number of presentations in each oddball sequence. The degree of SSA was quantified by the common SSA index (CSI) and the frequencyspecific SSA index (SI) reported previously (Ulanovsky et al., 2003, 2004; Malmierca et al., 2009; von der Behrens et al., 2009; Antunes et al., 2010; Pérez-González et al., 2012; Richardson et al., 2013). Both SSA indices reflect the difference between the neural responses to the deviant and standard stimuli, normalized to the sum of responses to both stimuli. The CSI averages the response to $f 1$ and $f 2$ while the SI quantifies them separately. The CSI is defined as CSI $=[d(f 1)+d(f 2)-s(f 1)-s(f 2)] /$ $[d(f 1)+d(f 2)+s(f 1)+s(f 2)]$, where $d(f)$ and $s(f)$ are responses to each frequency $f 1$ or $f 2$ when they were the deviant $(d)$ and standard $(s)$ stimuli, respectively. The SI was calculated separately for each frequency and it is defined as $\operatorname{SI}(f i)=[d(f i)-s(f i)] /[d(f i)+s(f i)]$, where $i=1$ or 2. Positive CSI and SI values indicate that the neurons responded more strongly to the frequencies when they were deviant compared to when they were standard. A CSI value of 0.1 was used as cutoff between neurons that exhibited or lacked SSA since it has been previously demonstrated that CSIs of $<0.1$ are not statistically different from zero and are due to random fluctuations in spike counts (Ayala et al., 2013). To test for effects of the drugs on each individual neuron, the $95 \%$ confidence intervals (CIs) for the baseline CSI were calculated using the bootstrapping method (1000 repetitions, Antunes and Malmierca, 2011; PérezGonzález et al., 2012). The limits of $95 \%$ CIs were calculated using the 2.5 and 97.5 percentiles of the CSI bootstrap distribution. An effect of the drug was considered to be significant when the CSI value obtained under the ejection condition was larger or smaller than the high or low $95 \% \mathrm{CI}$, respectively.

To characterize the time course of adaptation, we plotted the averaged response to the standard tone from all neurons as a function of the trial position. For each of $n$ trials, the sum of the raw number of spikes was divided by the total number of standard presentations that occurred at that $n$ trial (mean spikes per trial). The mean response was plotted at the original trial-long time scale. Then we performed a nonlinear leastsquare fit to this population mean curve to find the best-fitting double exponential function as follows: $f(t)=A_{\mathrm{ss}}+A_{\mathrm{r}} \cdot e^{-t / \tau(\mathrm{r})}+A_{\mathrm{s}} \cdot e^{-t / \tau(\mathrm{s})}$, where $A_{\mathrm{ss}}, A_{\mathrm{r}}$, and $A_{\mathrm{s}}$ are the magnitudes of the steady state and the rapid and slow components, respectively, and $\tau_{(\mathrm{r})}$ and $\tau_{(\mathrm{s})}$ are the time constants of the rapid and slow components (for details, see Pérez-González et al., 2012).

The best frequency (BF; sound frequency that evokes the maximal response), $\mathrm{CF}$, and threshold of each neuron were identified. Likewise, the response strength (spikes/stimulus) and response latency to the BF and $\mathrm{CF}$ were measured. The monotonicity index (MI; spike count at 80 $\mathrm{dB}$ SPL/maximum spike count), which refers to the degree of reduced spiking at higher intensities, was calculated from the FRA measure at the CF (Watkins and Barbour, 2011). Monotonic responses were those with an MI of $>0.75$. We measured the sharpness of the FRA by calculating the bandwidth and $Q$ value at 10 and $30 \mathrm{~dB}$ SPL above the threshold, as in previous studies (Hernandez et al., 2005; Izquierdo et al., 2008; Malmierca et al., 2009; Duque et al., 2012; Ayala et al., 2013). The bandwidth is the difference in kilohertz between the lowest and highest frequency of the FRA, and the $Q$ value is the CF divided by the bandwidth. Finally, the duration and temporal response patterns of the response to the $f 1$ and $f 2$ tones were visually determined to characterize the baseline neuronal response profiles. The temporal response patterns were classified following criteria used previously (Rees et al., 1997; Duque et al., 2012).

Since the presence of spontaneous activity can affect the SSA indices (Duque and Malmierca, 2014; Klein et al., 2014), we again calculated the SSA indices from the evoked activity, but after subtracting spontaneous activity. Spontaneous activity was estimated within a fixed $50 \mathrm{~ms}$ window before each tone presentation across all the trials of the oddball paradigm as described previously (Duque and Malmierca, 2014). Thus, for oddball sequences of 400 trials, a time sample of $20 \mathrm{~s}$ was obtained. Then, a corrected response was obtained by subtracting the average spontaneous activity from the evoked firing rate in the same window used before to evaluate SSA (evoked rate minus spontaneous rate in spikes per second). The subtraction was done bin by bin (bin size of $1 \mathrm{~s}$ ).

Unless stated otherwise, data are presented as the mean \pm SEM or the median \pm interquartile range, as appropriate. Differences in the SSA indices and strength and latency of the responses to deviant and standard tones across baseline, drug application, and recovery conditions were tested using a Friedman repeated-measures ANOVA on ranks test. Post hoc comparisons were performed following Dunn's method, and $p<$ 0.05 was considered statistically significant. To test for significant effects of drug application on a neuron's response features (i.e., spontaneous discharge, CF, MI, threshold), we performed a Wilcoxon signed rank test. To compare response baseline profiles between groups of neurons, we performed a Mann-Whitney ranks sum test or Kruskal-Wallis oneway ANOVA, as appropriate. Finally, to measure the strength of association between variables, we used the Spearman rank order correlation coefficient. Analyses and figures were executed using SigmaPlot version 11 (Systat Software) and Matlab 13 (MathWorks).

\section{Results}

To explore the influence of cholinergic neuromodulation on SSA in the IC of the rat, we recorded the responses of 152 well-isolated single neurons to an oddball paradigm before, during, and after microiontophoretic application of ACh $(n=105)$, scopolamine $(n=19)$, and mecamylamine $(n=28)$.

\section{The strength of the ACh effect depends on the baseline SSA level}

The recorded neurons had different temporal response patterns and exhibited (82\%) or lacked (18\%) SSA. Three example neurons are shown in Figure 1. The first neuron (Fig. $1 A$ ) responded with sustained firing of similar strength to both the deviant and standard tones across all the tone presentations; therefore, it lacks SSA (CSI baseline $_{1}$ 0.08). Microiontophoretic application of ACh did not change either the temporal response pattern or the ratio between the responses to the standard and deviant sounds as estimated by its CSI (CSI, 0.07; bootstrapping, 95\% CI; Fig. $1 A, B)$. Figure $1 C$ illustrates a neuron that showed an onset response type and a high level of SSA as depicted by its CSI (0.97). It was also unaffected by $\mathrm{ACh}$, even after a long period of application ( $>2$ h; Fig. $1 C, D)$. In contrast, Figure $1, E$ and $F$, depicts the response of a third neuron, with an intermediate CSI value (0.732), that was strongly affected by ACh. In this neuron, the firing response increased (Fig. $1 E$ ), and the CSI (0.41) decreased significantly, but returned to baseline values during recovery (Fig. $1 F$ ). Although Figure 1 illustrates the neuronal response to only one oddball sequence, the mean responses (spikes per trial) of the nonadapting (deviant, $f 1,7 \pm 0.11 ; f 2,8.15 \pm 0.12$; standard, $f 1,6 \pm 0.03 ; f 2,7.1 \pm 0.04$ ), highly adapting (deviant, f1, $1.02 \pm 0.05 ; f 2,0.5 \pm 0.07$; standard, $f 1,0.01 \pm 0.01 ; f 2,0.01 \pm$ 0.01 ), and partially adapting neurons (deviant, $f 1,1.6 \pm 0.09 ; f 2$, $2.1 \pm 0.08$; standard, $f 1,0.33 \pm 0.03 ; f 2,0.24 \pm 0.03)$ to $f 1$ and $f 2$ were similar whether they were presented as the deviant or the 

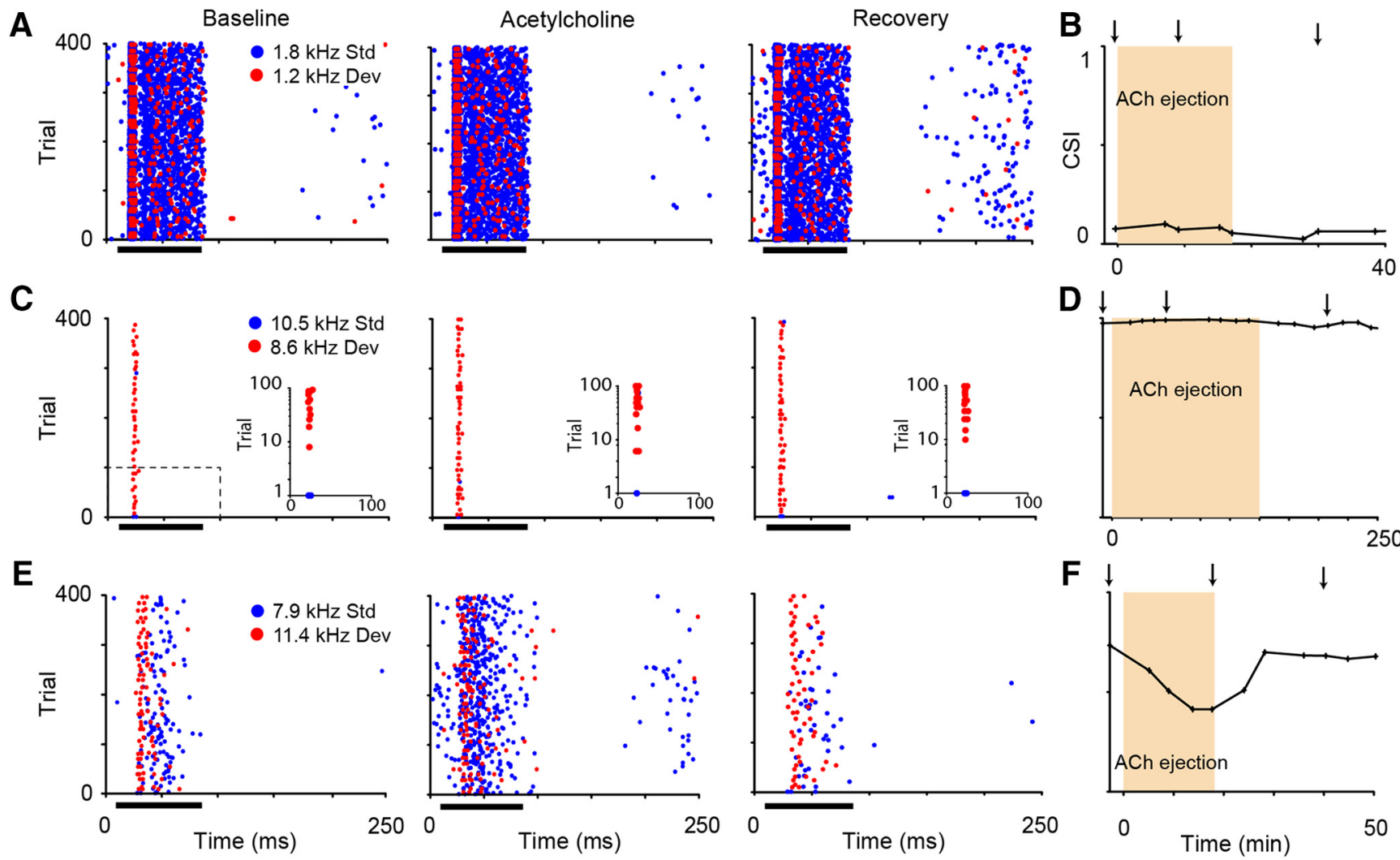

Figure 1. Examples of neurons recorded in this study. $A$, Dot rasters of the response to the oddball paradigm of an on-sustained neuron lacking SSA (CSI, 0.08$)$ under baseline, $A C h$, and recovery conditions. $\boldsymbol{B}$, Time course of the CSI before, during, and after the microiontophoretic ejection of ACh. Neither the firing response nor the CSI was changed by the ACh application (bootstrapping, $95 \%$ (I). C, Response of a neuron showing strong SSA (CSI, 0.97) with a distinct onset firing pattern that was unaffected by ACh (bootstrapping, $95 \%$ CI). The insets illustrate the first 100 trials of each oddball sequence in logarithmic scale. $\boldsymbol{D}$, As in $\boldsymbol{B}$, the CSI of the strongly adapting neuron remained unchanged. $\boldsymbol{E}$, Dot raster of the response of a neuron with moderate level of SSA (CSI, 0.73 ) that was profoundly affected by $\mathrm{ACh}$ showing an increase of firing rate. $\boldsymbol{F}$, The $\mathrm{CSI}$ of this partially adapting neuron decreased during $\mathrm{ACh}$ ejection (bootstrapping, $95 \% \mathrm{Cl})$. The tone duration $(75 \mathrm{~ms})$ is represented by the black bars in $\boldsymbol{A}, \boldsymbol{C}$, and $\boldsymbol{E}$. The duration of the ACh ejection is represented by the shaded areas in $\boldsymbol{B}, \boldsymbol{D}$, and $\boldsymbol{F}$. The small arrows in $\boldsymbol{B}, \boldsymbol{D}$, and $\boldsymbol{F}$ indicate the times of the dot rasters displayed for each neuron.

standard stimulus. Thus, the very few spikes shown in Figure $1 C$ are indeed due to adaption rather than to a lack of sensitivity to the standard tone.

Our data $(n=105)$ contain a wide range of CSI values from -0.06 to 0.99 (Fig. $2 A$ ) and thus include neurons that lack or exhibit different levels of SSA. Across the entire sample, the most remarkable finding was that ACh differentially affected only a subset of IC neurons (54 of 105; bootstrapping, 95\% CI), mainly by decreasing their CSIs ( 36 of 54). The majority of neurons with intermediate CSI values were sensitive to the ACh application $(0.1<$ CSI $<0.9 ; 43$ of 62$)$, whereas most of the neurons that exhibited low (CSI, $\leq 0.1 ; 15$ of 19 ) or high (CSI, $\geq 0.9 ; 17$ of 24 ) values were unaffected by ACh (Fig. $2 A$ ). The different baseline CSI values of our sample of neurons were fitted by a sigmoidal curve $\left(r^{2}=0.99, p<0.0001\right.$; Fig. $2 B$, gray line). We found that the magnitude of the absolute change exerted by ACh on the CSI followed a Gaussian distribution $\left(r^{2}=0.44, p<0.001\right.$; Fig. $2 B$, black line). The tails of the Gaussian curve correspond to the weak or absent effect exerted on neurons with low or extremely high CSI values, and the peak corresponds to the maximum effect exerted on neurons with intermediate CSI values. These results indicate a distinct dependence of the strength of the ACh effect on the baseline CSI. This dependence was also evident in the normalized responses to each frequency ( $f 1$ or $f 2$ ) estimated by the SIs (Fig. 2C). There was no difference between the absolute changes on SI1 and SI2 (Mann-Whitney rank sum test, $p=0.69$, $T=11250, n=105)$, indicating that ACh affected both frequen- cies similarly. Also, the absolute change exerted by ACh on the CSI correlated with the changes elicited on SI1 (Spearman's coefficient, $0.63 ; p=<0.001 ; n=2 \times 105$ ) and SI2 (coefficient, $0.59 ; p<0.001 ; n=2 \times 105 ;$ Fig. $2 D$ ). The magnitude of change on the SI was higher for the group of neurons with $0.1<\mathrm{CSI}<$ 0.9 , whereas for the neurons with CSI values of $\leq 0.1$ and $\geq 0.9$, this magnitude was similar (Kruskal-Wallis one way ANOVA, $p<0.001, H=38.76$; Dunn's method, $p<0.05 ; n=2 \times 105$ ). Hence, we can safely conclude that ACh decreased both the CSI and SI at the population level. The CSI decreased from $0.57 \pm$ 0.72 to $0.45 \pm 0.71$ (Friedman test, $p=0.01, X i^{2}=8.9, n=105$ ) and the SI from $0.57 \pm 0.69$ to $0.44 \pm 0.74$ (Friedman test, $p=$ $0.009, X i^{2}=9.36 ; n=2 \times 105$; Fig. $\left.2 E\right)$. The recovery values for most neurons were virtually identical to the baseline cases $\left(\mathrm{CSI}_{\mathrm{rec}}\right.$, $\left.0.52 \pm 0.66 ; \mathrm{SI}_{\text {rec }}, 0.53 \pm 0.74\right)$. Twelve neurons that were manipulated with ACh ( $11 \%$ of the sample) were lost before the full recovery. Nevertheless, those 12 neurons were distributed along the whole spectrum of CSI values in the sample and were similarly affected by ACh as other neurons with a similar baseline CSI. Furthermore, ACh increased the spontaneous rate (from $0.17 \pm$ 0.94 to $0.28 \pm 1.72$ spikes per second) of those IC neurons with partial levels of CSI $(0.1<\mathrm{CSI}<0.9$; Wilcoxon signed rank test, $W=476, Z$ statics $=2.441, p=0.015, n=62)$ but did not affect the spontaneous discharge of those with low (CSI, $\leq 0.1 ; p=0.23$; $n=19$ ) or high CSI values (CSI, $\geq 0.9 ; p=0.37 ; n=24$ ). Based on this result, we subtracted the spontaneous rate from the evoked response and recalculated the SSA indices of all neurons 
A

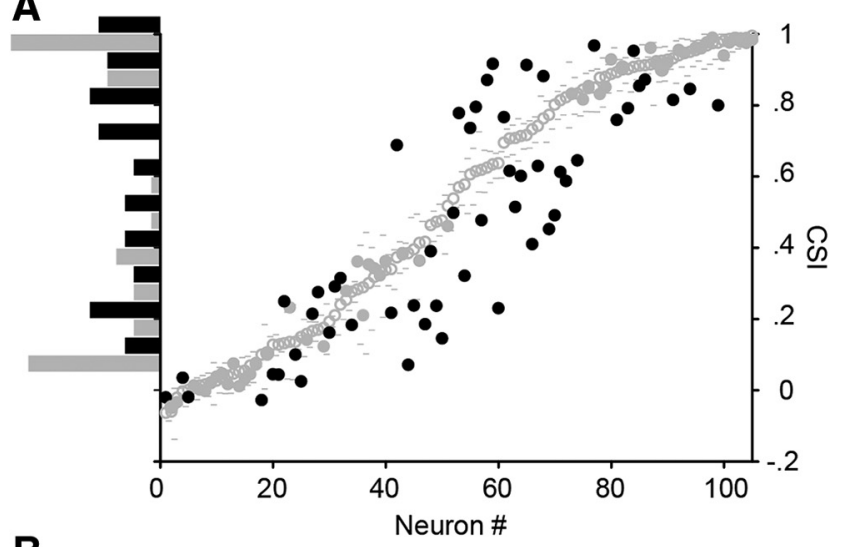

B

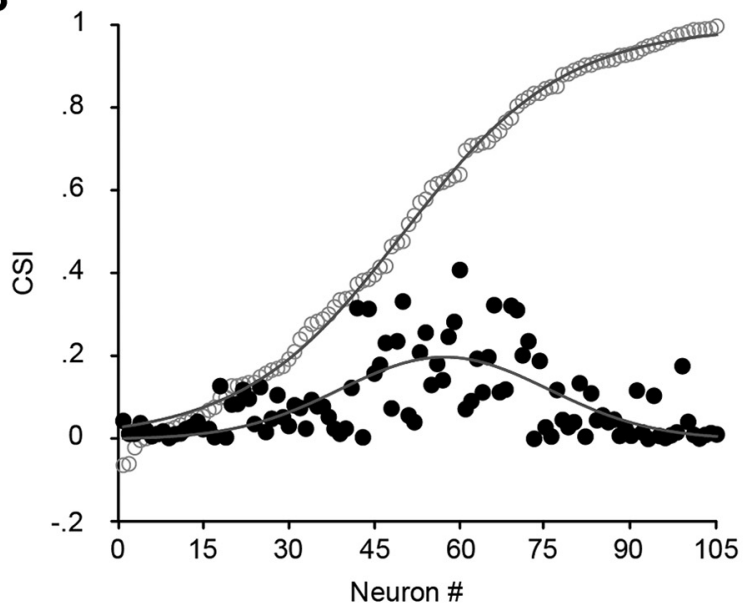

C
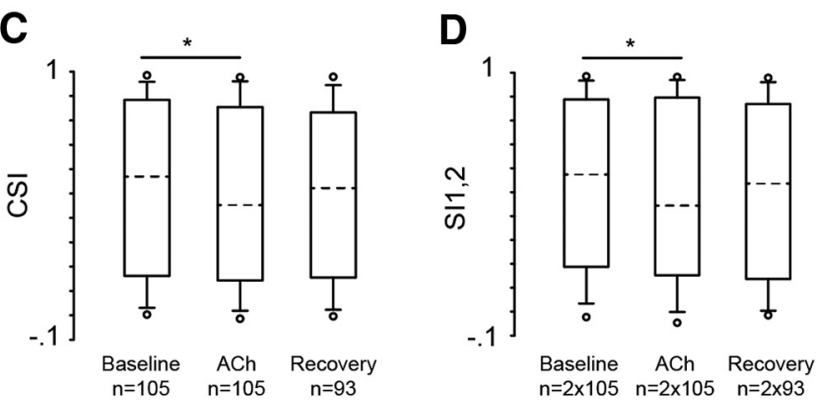

Figure 2. ACh effect on SSA in IC neurons. $A$, The recorded IC neurons showed different levels of CSI in the baseline condition (open circles) from -0.06 to 0.99 . The low and high $95 \% \mathrm{Cl}$ of each baseline (SI are displayed (gray dashes). The (SI of a subset of IC neurons changed during the application of ACh (black circles), being higher or lower than the CIs of the baseline CSI value, whereas another subset of IC neurons (gray circles) was insensitive to ACh application. Most of the neurons insensitive to ACh lacked SSA (CSI, $\leq 0.1$ ) or exhibited extremely high values (CSI, $\geq 0.9$ ) in the baseline condition (vertical histogram, left inset). $\boldsymbol{B}$, The strength of the effect of ACh depended on the baseline CSI. The baseline CSI values (open circles) were fitted by a Sigmoid curve $\left(r^{2}=0.99, p<0.001\right.$, gray line), whereas the absolute difference (black circles, expressed in positive values) between the baseline and ACh condition followed a Gaussian curve $\left(r^{2}=0.44, p<0.001\right.$, gray line). C, D, Box plots of the CSI (C) and SI1,2 (D) under the baseline, $A C h$, and recovery conditions. ACh decreased the SSA indices in the population of neurons (Friedman test). The dashed lines within each box represent the median values. The edges of the boxes delimit the 25 th and 75 th percentiles, the whisker bars extend to the 10th and 90th percentiles, and the circles represent the 95th and 5th percentiles. ${ }^{*} p<0.05$.

to validate that the changes we observed were due to an $\mathrm{ACh}$ effect on the driven responses. Under this manipulation, the SSA indices across the baseline, $\mathrm{ACh}$, and recovery conditions were increased, but ACh still decreased the CSI (Friedman test, $p=$
$0.01, X i^{2}=9.31, n=105$ ) and SI (Friedman test, $p=0.002$, $X i^{2}=12.04, n=2 \times 105$, Fig. $2 \mathrm{E}$ ), indicating a genuine cholinergic effect on the evoked responses.

\section{Acetylcholine differentially modulates the responses to deviant and standard tones}

In terms of spike count (spikes per trial), positive CSI values reflect smaller spike counts for the standard tone than for the deviant one. In agreement with this, the spike count for the standard sound was negatively correlated with the CSI (Spearman's coefficient, $-0.93 ; p<0.001 ; n=105$ ), whereas the response to the deviant sound elicited a weaker correlation (Spearman's coefficient, $-0.51 ; p<0.001 ; n=105)$. Across the whole population of neurons, the neural response was significantly affected by the ACh (Friedman test, $X i^{2}=405.112, p<0.001$ ). The post hoc analysis indicated that the spike count for the deviant tone was higher $(1.05 \pm 1.1$ spikes per trial) than for the standard tone $(0.26 \pm 0.96$ spikes per trial) in the baseline condition as expected, since our sample was biased to positive CSI values ( $p<$ 0.05 ). ACh increased the spike count for both the deviant and standard tones to $1.19 \pm 1.67$ and $0.42 \pm 1.36$ spikes per trial, respectively $(p<0.05)$, without eliminating the difference between them (Fig. $3 A, B$ ). In the recovery condition, the ACh effect on neural firing was completely abolished and the response decreased to baseline values $(1.12 \pm 1.27$ and $0.25 \pm 1.08$ for the deviant and standard tones, respectively; $p<0.05$ ). Since ACh did not affect the CSIs of all neurons and the strength of its effect was baseline dependent, next we explored how the spike count changed for those partially adapting neurons whose CSI was affected $(n=43)$. Most notably, for this group of neurons, we found that ACh increased only the responses to the standard tones (from $0.32 \pm 0.6$ to $0.51 \pm 1.13$ ), whereas the responses to deviant stimuli remained unchanged (baseline, $1.14 \pm 0.92 ; \mathrm{ACh}$, $1.39 \pm 1.45$; Friedman test, $X i^{2}=204.85, p<0.001$; Fig. $3 C, D$ ). Moreover, an effect on the responses to the standard but not to the deviant stimuli was also apparent for all neurons with a significant change in their CSI $\left(n=54\right.$; Friedman test, $X i^{2}=232.58$, $p<0.001)$.

We analyzed the effect of ACh on the time course of the response to the standard tone for those partially adapting neurons with a significant change in their CSI. The dynamics of the response to the standard tone was fit well by a double exponential function under the baseline $\left(r^{2}=0.79\right)$ and ACh $\left(r^{2}=0.78\right)$ conditions, displaying a rapid and a slow decay as well as a steadystate component (Fig. 3E). ACh increased the response during the steady-state component of the response from 0.63 spikes per trial $(95 \%$ CIs, $0.62,0.64)$ to 0.99 (95\% CIs, 0.98, 1; Fig. 3E) without affecting either the timing or the magnitude of the fast (baseline, $\tau_{\mathrm{r}}=0.62$ trial, $A_{\mathrm{r}}=4.97$ spikes per trial; $\mathrm{ACh}, \tau_{\mathrm{r}}=$ $0.59, A_{\mathrm{r}}=6.54$ ) or slow (baseline, $\tau_{\mathrm{s}}=29.15, A_{\mathrm{s}}=0.49 ; \mathrm{ACh}$, $\left.\tau_{\mathrm{s}}=26.7, A_{\mathrm{s}}=0.52\right)$ component of the adaptation.

The differential effects exerted by ACh on the responses to the standard and deviant tones were also reflected by the strength of correlation between the changes in the CSI $\left(\mathrm{CSI}_{\mathrm{ACh}}\right.$ minus $\mathrm{CSI}_{\text {baseline }}$ ) and spike count. The change in the CSI was correlated more strongly with the normalized change in the mean spiking response to $f 1$ and $f 2$ when presented as the standard tone $\left(r^{2}=\right.$ $-0.7, p<0.001, n=105)$ than with the change in the response to $f 1$ and $f 2$ when presented as the deviant tone $\left(r^{2}=-0.3, p<\right.$ 0.001 ; Fig. $3 F, G$ ).

We explored the effect of ACh on the first spike latencies (FSLs) of the responses to the deviant and standard tones as well as on the temporal response patterns. As expected from previous 
A

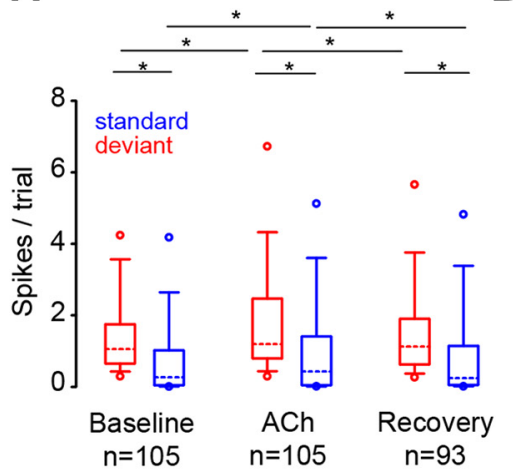

E

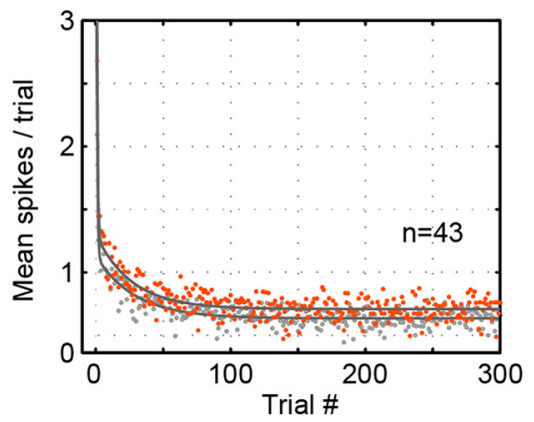

B
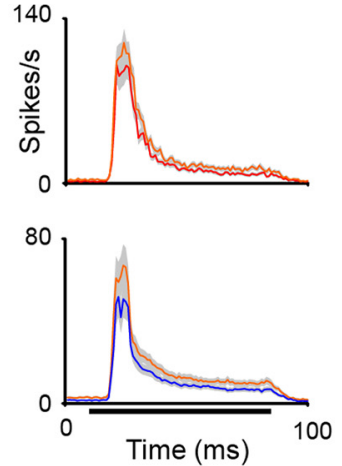

F
C

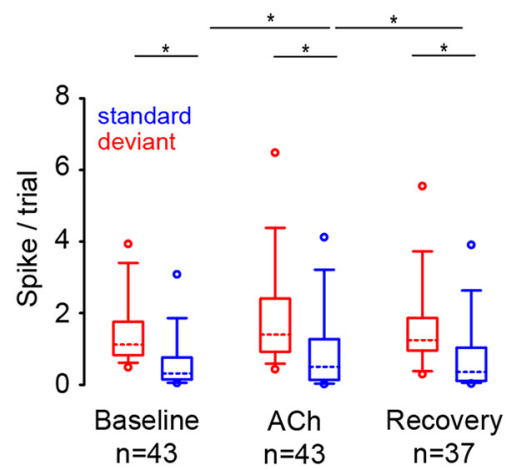

D
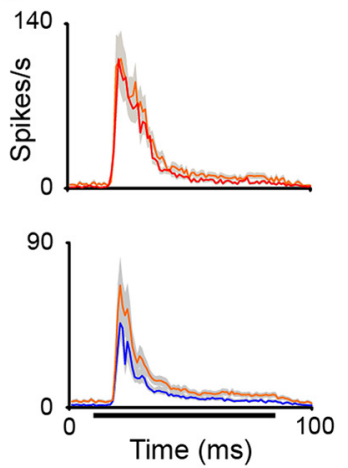

\section{G}

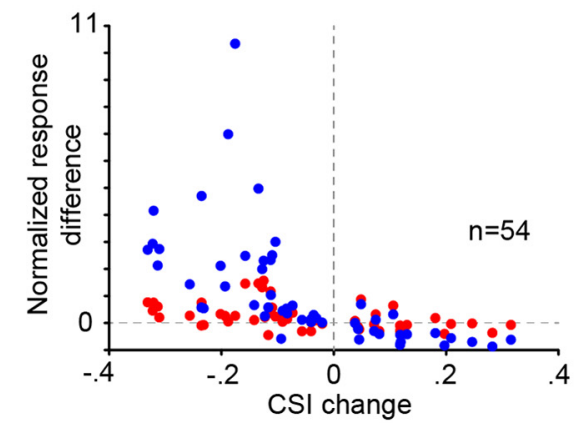

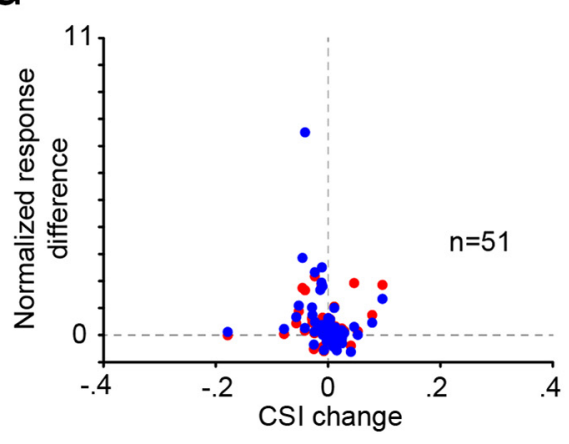

Figure 3. Effect of $A C h$ on the neural responses to deviant and standard sounds. $A$, Box plot of the responses to the deviant and standard tones of the whole population of $\mathrm{IC}$ neurons before, during, and after ACh ejection, indicating that ACh increased the responses to both tones. The box plot format is as in Figure 2, Cand D. B, Population PSTHs showing the baseline mean response for deviant (red line) and standard tones (blue line) and during the ACh ejection (-) as well as the SEMs of both PSTHs (shaded areas). The mean \pm SEM was calculated bin by bin (bin size, $1 \mathrm{~ms}$ ). The sound duration is indicated by the black bar. C, Box plot of the firing response for those neurons with $0.1<\mathrm{CSI}<0.9$ whose $\mathrm{CSI}$ was significantly affected by $\mathrm{ACh}$ (bootstrapping, $95 \%$ Cl). ACh increased only the response to the standard tone (Friedman test). The format is the same as in $\boldsymbol{A}$. D, Population PSTHs. The format is the same as in $\boldsymbol{B}$. $\boldsymbol{E}$, Time course of adaptation for the mean response to the standard tone for each position (trial) in the oddball sequence of neurons with $0.1<\mathrm{CSI}<0.9$ significantly affected by ACh. The baseline (open gray circles) and ACh data (orange circles) had fast and slow decay components and a steady-state component that were fitted by a double exponential function (gray lines). ACh increased only the steady-state component. $F$, Normalized change (ACh minus baseline) in the evoked response (mean spikes per trial) to deviant (red) and standard tones (blue) for those neurons whose CSI was changed (CSI ${ }_{A C h}$ minus $C S I_{\text {baseline }}$ ) by ACh application (bootstrapping, $95 \%$ Cl). $\boldsymbol{G}$, Normalized change in the evoked response as in $\boldsymbol{F}$, but for those neurons whose CSI was not affected by ACh (bootstrapping, $95 \%$ Cl). ${ }^{*} p<0.05$.

IC studies (Malmierca et al., 2009), the FSL of the deviant tone response (15.55 $\pm 7.41 \mathrm{~ms})$ was shorter than the FSL of the standard tone response $(16.19 \pm 8.7 \mathrm{~ms}, p<0.05)$ in the baseline condition. ACh did not affect the FSL; the response latency to the deviant tone remained shorter during the ACh ejection (deviant, $15.19 \pm 6.62 \mathrm{~ms}$; standard, $15.86 \pm 8.71 \mathrm{~ms}$ ) and recovery conditions (deviant, $15.61 \pm 7 \mathrm{~ms}$; standard, $15.71 \pm 8.69 \mathrm{~ms}$; Friedman test, $\left.X i^{2}=68.06, p<0.001\right)$. The shape of the peristimulus time histograms (PSTHs) was the same for deviant and standard tones and did not change with ACh application. Our sample of IC neurons showed mainly an onset response pattern (80\%), but also included on-sustained (9\%), pauser (6\%), long-latency onset $(3 \%)$, and sustained responses (2\%). From the 210 neural responses explored (each neuron had a response to both $f 1$ and f2), only 6 responses changed from onset to on-sustained. These results confirm that in the auditory midbrain of both awake (Habbicht and Vater, 1996) and anesthetized mammals (Farley et al., 1983), ACh affects the strength but not the temporal pattern of the neural responses.

To ensure that the lack of effect on the CSI we observed in some neurons was not due to a failed iontophoretic release of $\mathrm{ACh}$, we measured the CF, MI, and threshold of most of the neuronal FRAs (96 of 105) before and during the ACh application. We found that the threshold (Wilcoxon signed rank test, $W=-747, Z$ statics $=-4.03, p<0.001, n=96)$ and $Q_{10}$ value ( $W=-1423, p=0.009, n=96)$ were affected, whereas the CF
(Wilcoxon signed rank test, $W=-168, Z$ statics $=-0.84, p=$ $0.41, n=96)$ and $\mathrm{MI}(W=211, Z$ statics $=0.93, p=0.35, n=96)$ remained unchanged by ACh. Moreover, the thresholds of both groups of neurons, i.e., neurons with significant change in their CSI (Wilcoxon signed rank test, $W=-226, Z$ statics $=-2.97$, $p=0.003, n=50)$ and those whose CSI was unaffected by ACh $(W=-158, Z$ statics $=-2.75, p=0.006, n=46)$, were lowered from 30 to $20 \mathrm{~dB}$ SPL. These results demonstrate that the differential effects elicited by ACh on the CSI were genuine and not an artifact.

The effect of the ACh on SSA responses is mainly mediated by the mAChRs

Two major classes of cholinergic receptors (muscarinic and nicotinic) are distributed throughout the IC (Morley and Kemp, 1981; Clarke et al., 1985; Kelly and Caspary, 2005). To examine whether the ACh effects described above are mediated by the muscarinic and/or nicotinic receptors, we recorded 47 additional neurons before, during, and after the microiontophoretic application of their respective antagonists, i.e., scopolamine and mecamylamine. The application of scopolamine affected the CSI of 15 of 19 neurons (Fig. 4A), whereas the mecamylamine affected that of 16 of 28 neurons (Fig. $4 B$; bootstrapping, 95\% CI). The majority of the significantly affected neurons showed an increase in their CSI under the blockade of the muscarinic $(n=12$ of 15 ; Fig. $4 A)$ and nicotinic $(n=12$ of 16; Fig. $4 B)$ receptors. The 
A

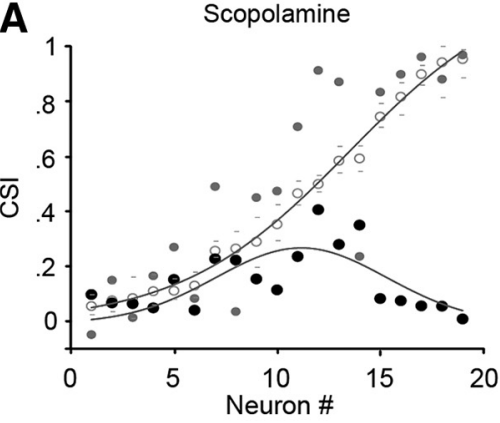

C

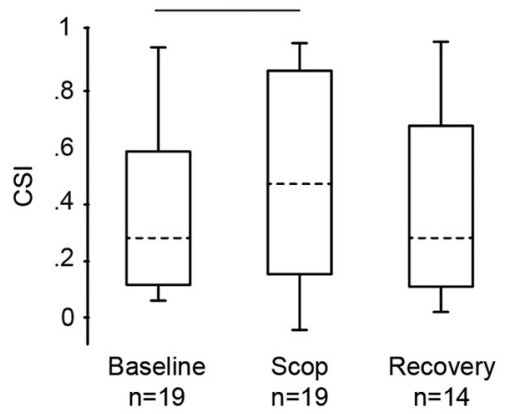

E

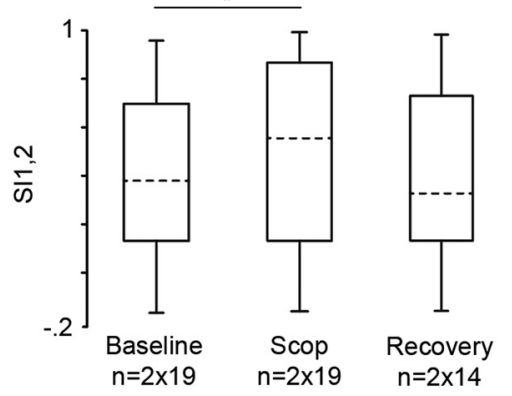

G

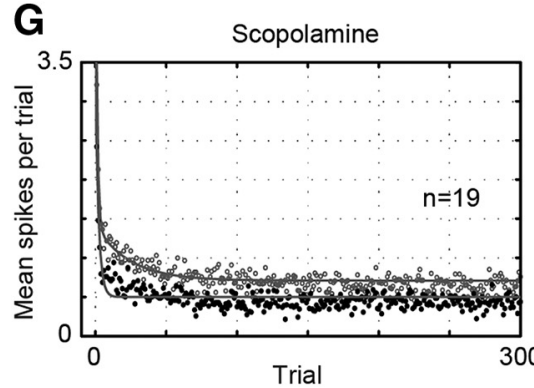

B

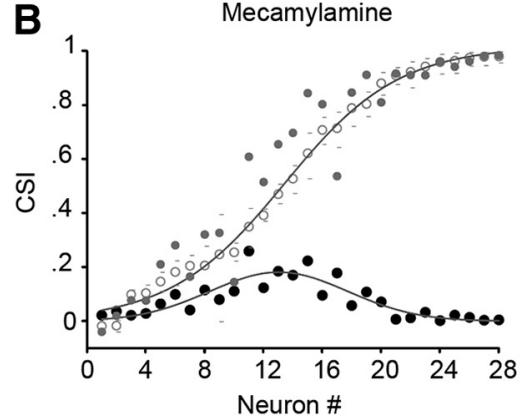

D
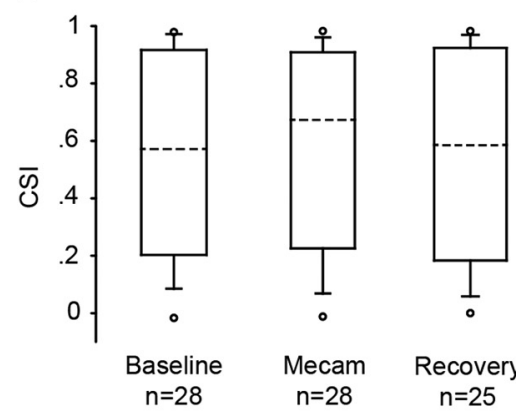

Recovery $\mathrm{n}=25$
$\mathbf{F}$

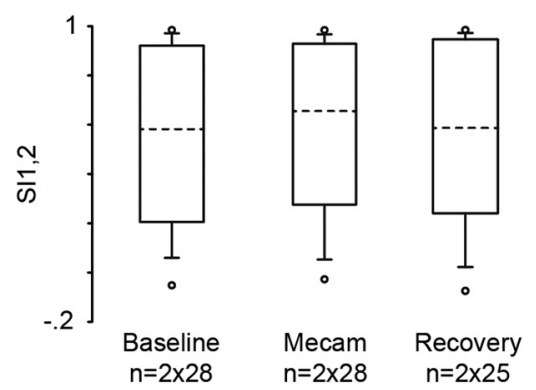

H

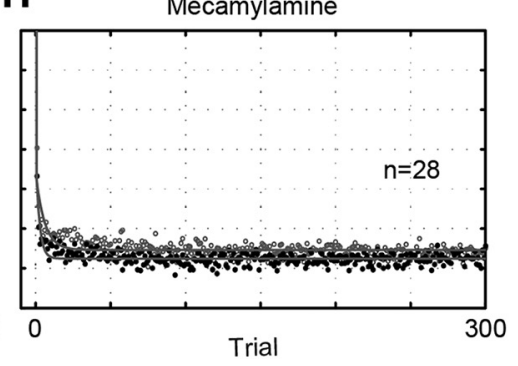

Figure 4. Effects of scopolamine and mecamylamine on SSA. $\boldsymbol{A}$, The blockade of muscarinic receptors by the application of scopolamine increased the CSI (gray circles) in most of the recorded IC neurons. The baseline CSI values (open circles) were fitted by a Sigmoidal curve $\left(r^{2}=0.99, p<0.001\right.$, gray line). The low and high $95 \%$ bootstrapped Cl values (gray dashes) are displayed for each baseline (SI. Similarly, the absolute differences (expressed in positive values) between the CSI in the baseline and scopolamine condition (black circles) were fitted by a Gaussian curve $\left(r^{2}=0.52, p<0.01\right.$, gray line). $\boldsymbol{B}$, Effect of nicotinic receptor blockade with mecamylamine. The format is the same as in $\boldsymbol{A}$ (Sigmoidal curve, $r^{2}=$ 0.99; Gaussian curve, $\left.r^{2}=0.76 ; p<0.001\right)$. C, Box plot of the population CSI showing that scopolamine (Scop) increased SSA as measured by the CSI (Friedman test). The box plot format is as in Figure 2, C and D. D, Box plot of the population CSI indicating that the mecamylamine (Mecam) application did not affect the SSA (Friedman test). $\boldsymbol{E}$, Box plot of the frequencyspecific SSA index for both frequencies $(S I 1,2)$ under the baseline, scopolamine and recovery condition. Scopolamine increased the SI (Friedman test). $\boldsymbol{F}$, Box plot of the SI1,2 indicating the lack of effect of mecamylamine (Friedman test). $\boldsymbol{G}$, Mean response to the standard tone for each position (trial) in the oddball sequence in the baseline (open circles) and scopolamine conditions (black circles). The responses were adjusted by a double exponential function (gray lines) with a fast and slow decay component and a steady-state part. Scopolamine decreased only the steady-state component. $\boldsymbol{H}$, Time course of the response under the baseline (open circles) and mecamylamine conditions (black circles). Mecamylamine did not affect the dynamics of adaptation. The format is the same as in $\mathbf{G . ~}^{*} p<0.05$.

magnitude of the effects of both antagonists exhibited the same dependence on baseline CSI value as ACh. The greatest changes elicited by the scopolamine and mecamylamine were on neurons with intermediate CSI values, and the absolute changes followed a Gaussian distribution $\left(r^{2}=0.52, p=0.003\right.$ and $r^{2}=0.76, p<$ 0.001 , respectively; Fig. $4 A, B)$.

At the population level, only scopolamine significantly increased the CSI (Friedman test, $X i^{2}=7, p=0.03, n=19$; Fig. $4 C$ ). Neurons with $0.1<$ CSI $<0.9$ $(n=14)$ were the most affected by scopolamine. The absolute CSI change was $0.16 \pm 0.15$ for this group. Mecamylamine application did not significantly increase the CSI of the whole population (Friedman test, $X i^{2}=1.52, p=0.47, n=$ 28; Fig. 4D) nor that of the group of neurons with $0.1<\mathrm{CSI}<0.9$ values (Friedman test, $X i^{2}=5.286, p=0.071, n=17$ ). The magnitude of absolute change for the group of $0.1<\mathrm{CSI}<0.9$ neurons was $0.11 \pm 0.10$. Likewise, the SI was affected by scopolamine (Friedman test, $X i^{2}=$ 7.36, $p=0.02, n=38$; Fig. $4 E, F)$, but not by mecamylamine (Friedman test, $p=$ 0.36, $X i^{2}=2.02, n=56$; Fig. $\left.4 E, G\right)$. The lack of effect of mecamylamine across the whole sample of neurons might be due to the higher proportion of neurons (11 of 28 ) with very low (CSI, $\leq 0.1)$ and very high CSI values (CSI, $\geq 0.9$ ) compared with the sample of neurons tested under scopolamine (5 of 19). The blockade of the cholinergic receptors decreased the response only to the deviant tone (Friedman test, $p<0.001)$. The driving response changed from $1.17 \pm 1.52$ to $0.95 \pm 0.63$ spikes per trial under the scopolamine ejection (Friedman test, $X i^{2}=66.37, p<$ 0.001; Dunn's method, $p<0.05 ; n=38$ ), and from $1.28 \pm 1.17$ to $0.95 \pm 0.83$ spikes per trial (Friedman test, $X i^{2}=148.84, p<$ 0.001; Dunn's method, $p<0.05, n=56$ ) under mecamylamine application. Although the mean population response to the standard tone was not significantly affected, we observed a clear change in the temporal course of adaptation elicited by muscarinic and nicotinic blockade (Fig. $4 H, I)$. The standard responses of those neurons with intermediate $(0.1<\mathrm{CSI}<$ $0.9)$ and significant changes in their CSI under scopolamine $\left(r^{2}=0.66, n=13\right)$ and mecamylmine application $\left(r^{2}=0.61\right.$, $n=14$ ) were fitted by the double exponential function described previously for ACh. We found that scopolamine caused a greater decrease in the response during the steady state compared with mecamylamine. Scopolamine led to a 53\% reduc- 
tion in the steady-state component of adaptation (Fig. $4 H$ ), from 0.61 spikes per trial $(95 \%$ CIs, $0.59,0.63)$ to 0.29 (95\% CIs, 0.27, 0.29), whereas mecamylamine (Fig. $4 I$ ) caused a decrease of only $29 \%$, from 0.50 ( $95 \%$ CIs, $0.49,0.52)$ to 0.36 spikes per trial (95\% CIs, 0.34, 0.37). The magnitude and timing of the rapid and slow decays of the response to the standard tone were not affected by cholinergic blockade.

\section{Anatomical and physiological correlates of the ACh effect}

We determined the location of the majority of the recorded neurons (64 of 105) across IC subdivisions. Most of the neurons were located in the RCIC $(n=34)$, and the remaining neurons were distributed in the LCIC $(n=17)$ and CNIC $(n=$ 13). The baseline CSI was higher in the cortical subdivisions (RCIC, $0.62 \pm 0.57$; LCIC, $0.72 \pm 0.45)$ than in the central nucleus $(0.13 \pm 0.23$; Kruskal-Wallis one way ANOVA, $H=12.98, p=0.002$; Fig. $5 A)$. Interestingly, the magnitude of change exerted on the CSI by $\mathrm{ACh}$ in RCIC and LCIC neurons followed the same Gaussian distribution as the whole population depicted in Figure $2 B\left(r^{2}=\right.$ 0.47, $p<0.0001$ and $r^{2}=0.47, p=0.01$, respectively; Fig. $5 B, C$ ), whereas the sample of neurons from the CNIC showed a weak effect that did not follow a Gaussian distribution ( $p=1$; Fig. $5 D)$.

Finally, we explored whether response properties other than the degree of SSA were affected by ACh. First, we found that the neuron's spontaneous discharge rate, response strength to $\mathrm{BF}$, response strength and response latency to $\mathrm{CF}$, and bandwidth and $Q$ value at $30 \mathrm{~dB}$ SPL above threshold correlated with CSI levels (Spearman's coefficient, $p=<0.05$; Table 1). Second, when these parameters were compared between groups of neurons affected $(n=54)$ or unaffected $(n=51)$ by ACh, we observed differences only in the spontaneous discharge (unaffected, $42 \pm 53.75$ spikes per second; affected, $67.5 \pm 47$ ), response strength (unaffected, $3 \pm 3.56$ spikes per stimulus; affected, $4.25 \pm 5.25$ ), and latency (unaffected, $13.91 \pm 8.46 \mathrm{~ms}$; affected, $10.17 \pm 2.76$ ) to BF and in the MI (unaffected, $0.92 \pm 0.33 \mathrm{~ms}$; affected, $1 \pm 0.20)$. The lack of consistent differences between groups might be due to an averaging out due to pooling neurons with extreme response features in the unaffected CSI group. Also, these data indicate that there is a continuum of neuronal response types with different response features and sensitivities to cholinergic modulation instead of two segregated neural populations, i.e., sensitive and insensitive to ACh.

\section{Discussion}

We demonstrated that application of ACh decreases the SSA of IC neurons by increasing the response to the standard tone and that this effect is mainly mediated by muscarinic receptors. Moreover, we found that the strength of the cholinergic modulation depends on the baseline SSA level, exerting its greatest effect on neurons with intermediate SSA responses. To the best of our knowledge, this is the first study demonstrating that auditory SSA is sensitive to cholinergic modulation.

A selective effect of ACh on frequency processing has been described in AC neurons of anesthetized animals. A repeated single-frequency stimulus simultaneously paired with the iontophoretic application of ACh (Metherate and Weinberger, 1989, 1990) or electrical stimulation of the nucleus basalis (Bakin and Weinberger, 1996) produced a highly specific change in the response to the paired frequency rather than a general change in excitability. More recent studies in the AC (Froemke et al., 2007; Froemke et al., 2013) using an ACh-tone pairing protocol indicated that ACh exerts transient synaptic disinhibition by shifting first the excitatory tuning curves followed by a delayed change in inhibitory tuning, i.e., producing a stimulus-specific decrease in tone-evoked inhibition (Froemke, 2015). These studies have led to the notion that cholinergic disinhibition leads to long-term potentiation and heterosynaptic plasticity of excitation and inhibition after repetitive sensory stimulation (Froemke, 2015). Since the synapses activated by the standard tone were more active under ACh application, it is possible that similar synaptic plasticity mechanisms underlie the selective increase in the response to the standard tone.

The observed decrease in the adaptation to the standard tones also agrees with diminished spike-frequency adaptation caused by ACh in other sensory areas (Metherate et al., 1992; McCormick, 1993; Martin-Cortecero and Nunez, 2014). Likewise, ACh affected SSA mainly through the activation of the muscarinic rather than the nicotinic receptors (Fig. 4G,H). A previous iontophoretic study suggests that muscarinic receptors are the most predominant cholinergic receptors in the IC (Watanabe and Simada, 1973). Muscarinic receptors are expressed both presynaptically and postsynaptically, so they can alter the excitability of the 
Table 1. Physiological response properties of the recorded IC neurons

\begin{tabular}{|c|c|c|c|c|c|c|c|c|c|c|c|c|c|c|c|}
\hline $\begin{array}{l}\text { CSI } \\
\text { interval }\end{array}$ & $n$ & $\begin{array}{l}\text { Response } \\
\text { duration } \\
\text { (ms) }\end{array}$ & $\begin{array}{l}\text { Spontaneous } \\
\text { discharge } \\
\text { (spikes/s) }\end{array}$ & $\begin{array}{l}\text { Threshold } \\
\text { (dBSPL) }\end{array}$ & $\mathrm{BF}(\mathrm{kHz})$ & $\begin{array}{l}\text { Response } \\
\text { to BF } \\
\text { (spikes/stim) }\end{array}$ & $\begin{array}{l}\text { Response } \\
\text { latency } \\
\text { to BF (ms) }\end{array}$ & $\mathrm{CF}(\mathrm{kHz})$ & $\begin{array}{l}\text { Response } \\
\text { to CF } \\
\text { (spikes/stim) }\end{array}$ & $\begin{array}{l}\text { Response } \\
\text { latency } \\
\text { to CF (ms) }\end{array}$ & Ml at $C F$ & $\mathrm{BW}_{10}$ & $Q_{10}$ & $\mathrm{BW}_{30}$ & $Q_{30}$ \\
\hline$\leq 0.1$ & 19 & $69 \pm 5.35$ & $2.54 \pm 1.39$ & $37 \pm 3$ & $10.03 \pm 1.41$ & $6.39 \pm 1.1$ & $13.82 \pm 1.09$ & $12.36 \pm 1.69$ & $1.39 \pm 0.26$ & $17.31 \pm 0.92$ & $0.84 \pm 0.05$ & $6.61 \pm 1.18$ & $2.2 \pm 0.25$ & $15.9 \pm 3.75$ & $0.948 \pm 0.13$ \\
\hline$\leq 0.2$ & 11 & $71.46 \pm 6.98$ & $2.48 \pm 1.37$ & $28 \pm 5$ & $11.35 \pm 2.51$ & $9.88 \pm 3.24$ & $14.83 \pm 4.25$ & $12.19 \pm 1.7$ & $1.93 \pm 0.46$ & $18.55 \pm 2.13$ & $0.88 \pm 0.08$ & $9.23 \pm 1.37$ & $1.43 \pm 0.22$ & $16.04 \pm 5.35$ & $1.21 \pm 0.39$ \\
\hline$\leq 0.3$ & 6 & $54.17 \pm 13.25$ & $0.49 \pm 0.2$ & $15 \pm 2$ & $8.14 \pm 1.06$ & $7.13 \pm 2.37$ & $10.16 \pm 0.26$ & $10.02 \pm 0.54$ & $1.71 \pm 0.83$ & $18.28 \pm 2.47$ & $0.79 \pm 0.16$ & $8.38 \pm 2.71$ & $2.5 \pm 0.94$ & $13.44 \pm 5.48$ & $1.74 \pm 0.63$ \\
\hline$\leq 0.4$ & 9 & $55.33 \pm 8.71$ & $5.22 \pm 2.68$ & $21 \pm 3$ & $10.26 \pm 2.44$ & $4.78 \pm 0.77$ & $12.06 \pm 1.49$ & $13.66 \pm 2.1$ & $1.61 \pm 0.49$ & $17.16 \pm 1.68$ & $0.75 \pm 0.11$ & $13.09 \pm 2.82$ & $1.57 \pm 0.42$ & $18.08 \pm 6.03$ & $1.03 \pm 0.27$ \\
\hline$\leq 0.5$ & 5 & $47 \pm 15.18$ & $0.04 \pm 0.03$ & $34 \pm 7$ & $7.99 \pm 0.92$ & $3.2 \pm 0.92$ & $10.24 \pm 1.58$ & $13.50 \pm 3.64$ & $1.1 \pm 0.54$ & $14.49 \pm 1.72$ & $0.83 \pm 0.17$ & $7.68 \pm 3.07$ & $2.75 \pm 1.14$ & $13.55 \pm 6.77$ & $1.36 \pm 0.28$ \\
\hline$\leq 0.6$ & 4 & $51.25 \pm 11.25$ & $0.8 \pm 0.74$ & $30 \pm 4$ & $4.26 \pm 2.08$ & $2.94 \pm 1.6$ & $16.24 \pm 6.82$ & $11.61 \pm 7.09$ & $0.92 \pm 0.22$ & $28.56 \pm 7.24$ & $0.43 \pm 0.19$ & $6.15 \pm 2.29$ & $1.41 \pm 0.5$ & $8.87 \pm 4.44$ & $0.97 \pm 0.3$ \\
\hline$\leq 0.7$ & 7 & $41.43 \pm 7.69$ & $1.09 \pm 0.64$ & $17 \pm 4$ & $10.76 \pm 1.32$ & $5.29 \pm 0.98$ & $10.95 \pm 0.97$ & $13.24 \pm 1.43$ & $0.98 \pm 0.15$ & $19.77 \pm 1.76$ & $0.95 \pm 0.03$ & $10.12 \pm 2.05$ & $1.62 \pm 0.27$ & $23.34 \pm 8.82$ & $0.72 \pm 0.14$ \\
\hline$\leq 0.8$ & 8 & $55.63 \pm 7.83$ & $0.34 \pm 0.14$ & $30 \pm 5$ & $10.57 \pm 1.4$ & $4.84 \pm 1.25$ & $11.29 \pm 1.53$ & $12.52 \pm 2.37$ & $1.09 \pm 0.18$ & $20.56 \pm 1.85$ & $1 \pm 0$ & $16.37 \pm 4.16$ & $1.26 \pm 0.34$ & $27.26 \pm 9.64$ & $0.58 \pm 0.18$ \\
\hline$\leq 0.9$ & 12 & $54.75 \pm 7.46$ & $0.25 \pm 0.11$ & $23 \pm 4$ & $15.03 \pm 2.75$ & $3.33 \pm 0.69$ & $11.78 \pm 1.2$ & $17.05 \pm 2.38$ & $0.96 \pm 0.16$ & $25.39 \pm 4.28$ & $0.84 \pm 0.05$ & $11.15 \pm 1.71$ & $1.7 \pm 0.21$ & $23.35 \pm 6.74$ & $0.84 \pm 0.15$ \\
\hline$\leq 1$ & 24 & $42.67 \pm 4.48$ & $0.16 \pm 0.08$ & $28 \pm 2$ & $11.77 \pm 1.9$ & $2.76 \pm 0.25$ & $16.84 \pm 1.54$ & $14.12 \pm 1.62$ & $0.97 \pm 0.13$ & $21.86 \pm 1.3$ & $0.78 \pm 0.06$ & $10.29 \pm 1.39$ & $1.58 \pm 0.15$ & $23.37 \pm 4.87$ & $0.69 \pm 0.08$ \\
\hline $\begin{array}{l}\text { Correlation } \\
\text { coefficient }\end{array}$ & & -0.61 & $-0.65^{*}$ & -0.09 & 0.48 & $-0.7^{*}$ & 0.12 & $0.81^{* *}$ & $0.78^{* *}$ & $0.66^{*}$ & 0.08 & 0.52 & -0.25 & $0.65^{*}$ & $-0.7^{*}$ \\
\hline
\end{tabular}

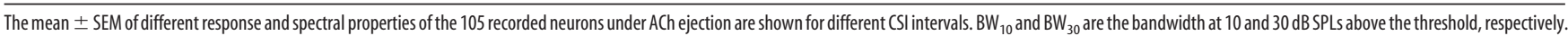
The bandwidth is the frequency width of the frequency response area of each neuron at the specified intensities. $Q_{10}$ and $Q_{30}$ are the quality factors reflecting the relative sharpness of tuning by the $C F$ divided by the bandwidth at 10 and 30 $\mathrm{dB}$ SPLS above the threshold, respectively. Some of those response properties correlated with the CSI. stim, Stimulus.

${ }^{*} p<0.05 ;{ }^{* *} p<0.01$ (Spearman's coefficient).

neurons as well as the release probability of other neurotransmitters (Zhang et al., 2002; Thiele, 2013). In the IC, at least two types of muscarinic receptors (M1 and M2 types) can modify neural firing (Habbicht and Vater, 1996). Since we used scopolamine, which is a general antagonist for muscarinic receptors, we cannot discriminate between the effects of the two muscarinic subtypes, but it is likely that most of the excitatory effect exerted by ACh was mediated by the activation of the M1 type, since selective blockade of the M1 receptor mostly leads to inhibition, whereas the opposite effect occurs with selective blockade of the M2 type (Habbicht and Vater, 1996).

The excitatory effects elicited by ACh might be mediated through the regulation of $\mathrm{K}^{+}$channels (McCormick and Prince, 1986; Krnjević, 2004). The activation of the M1-type receptor induces a reduction in hyperpolarizing potassium currents through the closure of $\mathrm{K}^{+}$channels such as the slow afterhyperpolarization $\mathrm{K}^{+}$channel or the inward-rectifier $\mathrm{K}^{+}$type 2 channel, which in turn reduces spike frequency adaptation and increases driven and spontaneous activity (Cole and Nicoll, 1984; Krause and Pedarzani, 2000; Thiele, 2013). Changes in potassium conductance can act as an activity-dependent adaptation mechanism (Sanchez-Vives et al., 2000a,b) that contributes to a significant fraction of cortical auditory adaptation (Abolafia et al., 2011). For those reasons, $\mathrm{K}^{+}$-mediated adaptation has been proposed as a potential mechanism underlying SSA (Abolafia et al., 2011; Malmierca et al., 2014). ACh might also increase the toneevoked responsivity in the IC by modulating the release of other neurotransmitters as reported in the AC (Metherate, 2011), where the activation of cholinergic receptors decreases the release of GABA from interneurons (Salgado et al., 2007) or elicits the activation of NMDA receptor-mediated glutamatergic neurotransmission (Metherate and Hsieh, 2003; Metherate, 2004; Liang et al., 2008).

It is worth mentioning here that the present results do not exclude a prominent role of the nicotinic receptors in shaping SSA. In vitro studies in neocortical neurons suggest that ACh ejection favors the activation of the muscarinic receptors over nicotinic receptors because of the different synaptic distribution and time course of desensitization and inactivation of their currents (Hedrick and Waters, 2015). ACh ejection, compared with $\mathrm{ACh}$ release from cholinergic axons (as, for example, elicited by optogenetic manipulation), results in a relatively slow and widespread increase, more likely activating muscarinic receptors that are located extrasynaptically. Although, we used the most gener-
Activation of cholinergic receptors

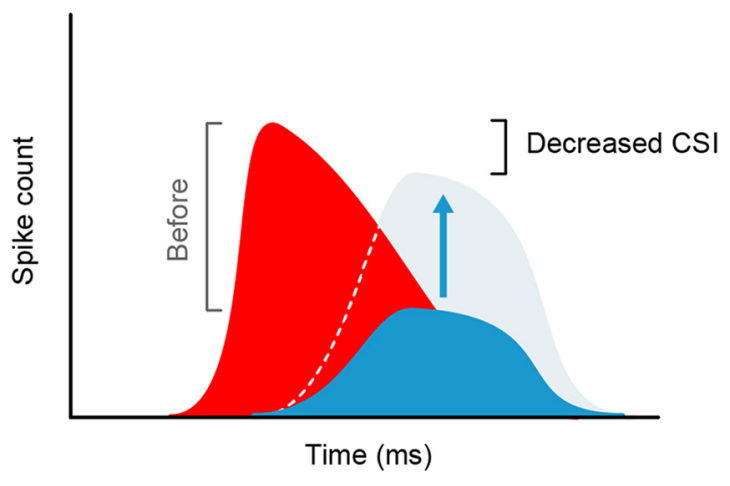

Figure 6. Schematic diagram of the effect of acetylcholine on the responses of IC neurons. The microiontophoretic application of acetylcholine decreased the CSI by selectively increasing the responses to the standard tone (baseline, solid blue; ACh ejection, light blue). Note that the responses to the deviant tone (red) were virtually unaffected.

ally used concentration of the cholinergic antagonists (Farley et al., 1983), and we cannot rule out that other concentrations may yield different results. The role of the biophysical properties of the cholinergic receptor subtypes and the impact of ACh concentrations on SSA modulation require further study.

Our finding that ACh exerts a very delicate modulation by selectively increasing the evoked response to the standard sound (Fig. 6) contrasts with the previously described gain control that is exerted by $\mathrm{GABA}_{\mathrm{A}}$-mediated inhibition (PérezGonzález et al., 2012; Duque et al., 2014). The blockade of the $\mathrm{GABA}_{\mathrm{A}}$ receptors exerts a dramatic, overall increase in the neural responsiveness of IC neurons to both deviant and standard tones (Pérez-González et al., 2012). Likewise, our finding showing that cholinergic manipulation (Figs. $3 E, 4 H, I$ ) affected only the steady state of the time course of adaptation markedly contrasts with the substantial changes affecting the fast and slow decays of adaptation when the $\mathrm{GABA}_{\mathrm{A}}$ receptors were blocked or activated. In agreement with our observations on the evoked response (Fig. $3 A-E$ ) and FSL, a change in strength but not in latency was found to be elicited by ACh in somatosensory cortical neurons (Martin-Cortecero and Nunez, 2014). From these results, we can conclude that ACh in the IC contributes to maintenance of the encoding of repetitive acoustical input by decreasing adaptation. This appears to 
occur mainly through the activation of muscarinic receptors and acts at a different time course than that of GABAergic inhibition.

The absent, modest, or profound effects of ACh on SSA (Figs. $2 B, 4 A, B, 5 B)$ might be explained by differences in the membrane potential of the neurons, expression of different subtypes of cholinergic receptors, and/or the strength of cholinergic inputs. These factors may enable IC neurons with partial levels of SSA to filter sensory information according to different global brain states (e.g., deep sleep, wakefulness, attention). Neurons exhibiting extreme SSA could play a more prominent role as specialized filters for redundant information insensitive to fine modulation. Likewise, it is possible that the strength of the cholinergic modulation on SSA would depend on the context of stimulation (e.g., relative deviant and standard probabilities or stimulation rate) able to elicit different levels of SSA on the same neuron (Malmierca et al., 2009; von der Behrens et al., 2009; Ayala et al., 2013). These issues require further analysis and follow-up experiments.

Cortical and subcortical SSA show many similarities. For example, both show multiple time scales of adaptation and frequency hyperacuity (Ulanovsky et al., 2003; Malmierca et al., 2009; Ayala et al., 2013). However, cortical SSA is stronger in the sustained component of the neural responses (Ulanovsky et al., 2003), whereas subcortical SSA is stronger in the onset part (Duque et al., 2012). Thus, SSA occurring in the AC and in the IC may play different roles (Nelken, 2014). Moreover, due to their different sources of cholinergic projections, we cannot generalize our results to ACh effects on cortical SSA. The main source of $\mathrm{ACh}$ to the AC is the basal forebrain (Edeline et al., 1994; Zaborszky et al., 2012; Bajo et al., 2014), while cholinergic input to the IC originates in the pontomesencephalic tegmentum (PMT; Motts and Schofield, 2009; Schofield, 2010). These different ACh sources may constitute two parallel pathways for modulating change detection in the AC and IC. However, it is likely that changes in cortical excitability may affect subcortical SSA by triggering the release of $\mathrm{ACh}$, since $\mathrm{AC}$ neurons innervate the PMT cholinergic neurons that project to the IC (Schofield and Motts, 2009; Schofield, 2010). Deactivation of the AC exerts a heterogeneous control on SSA in the IC (Anderson and Malmierca, 2013) that could be indirectly mediated by ACh through a disynaptic $\mathrm{AC} \rightarrow \mathrm{PMT} \rightarrow$ IC projection. Thus, different states of cortical activation might exert a top-down control on the sensory signals being processed at the IC by gating the PMT cholinergic input. The presence of neurons either sensitive or insensitive to ACh within the same IC subdivision (Fig. $5 A$ ) together with tracktracing data (Schofield, 2010; Schofield et al., 2011) and radiolabeling studies of cholinergic receptors (Rotter et al., 1979; Clarke et al., 1984, 1985; Cortés and Palacios, 1986) suggest that the cholinergic projection is diffuse throughout the IC and targets specific synaptic domains populated by neurons with intermediate SSA. Alternatively, ACh may modulate specific features such as the spectral sensitivity of one type of neuron and the SSA of others.

We found that the microiontophoretic application of ACh in the IC of the anesthetized rat reduces SSA, which is consistent with the low SSA indices observed in awake animals (von der Behrens et al., 2009; Duque and Malmierca, 2014) where ACh levels are higher (Kametani and Kawamura, 1990; Marrosu et al., 1995). Furthermore, we found that ACh increased sensitivity to frequencies at the limen of detectability by decreasing the threshold and broadening the spectral tuning of the FRAs. This result suggests an improvement in the encoding abilities of IC neurons under cholinergic modulation. Rapid and dynamic plastic changes of the receptive fields are also known to occur in auditory cortical neurons under behavioral tasks that engage attentional demands (Fritz et al., 2003, 2005, 2007a,b) as well as immediately after the electrical stimulation of the nucleus basalis (Bakin and Weinberger, 1996; Kilgard and Merzenich, 2002; Froemke et al., 2013).

Our finding that local augmentation of ACh increases neural excitability (Fig. $3 A$ ) and attenuates adaptation to a repetitive sound (Fig. $3 E$ ) agrees with the effect of systemic manipulation of ACh levels on population neural sensitivity to repetitive sounds. Recently, using blocks of tone repetitions in an electroencephalographic study in humans, Moran et al., 2013 found that the decreased responses to consecutive presentation of the same tone (i.e., repetition suppression) were markedly attenuated by systemic application of galantamine, an acetylcholinesterase inhibitor.

In conclusion, we showed that ACh exerts transient functional changes in partially adapting IC neurons, enhancing the sensory encoding of repetitive stimuli. This effect might potentially contribute to the propagation of ascending sensory-evoked afferent signals through the thalamus en route to the cortex.

\section{References}

Abolafia JM, Vergara R, Arnold MM, Reig R, Sanchez-Vives MV (2011) Cortical auditory adaptation in the awake rat and the role of potassium currents. Cereb Cortex 21:977-990. CrossRef Medline

Anderson LA, Malmierca MS (2013) The effect of auditory cortex deactivation on stimulus-specific adaptation in the inferior colliculus of the rat. Eur J Neurosci 37:52-62. CrossRef Medline

Antunes FM, Malmierca MS (2011) Effect of auditory cortex deactivation on stimulus-specific adaptation in the medial geniculate body. J Neurosci 31:17306-17316. CrossRef Medline

Antunes FM, Nelken I, Covey E, Malmierca MS (2010) Stimulus-specific adaptation in the auditory thalamus of the anesthetized rat. PLoS One 5:e14071. CrossRef

Ashe JH, McKenna TM, Weinberger NM (1989) Cholinergic modulation of frequency receptive fields in auditory cortex: II. Frequency-specific effects of anticholinesterases provide evidence for a modulatory action of endogenous ACh. Synapse 4:44-54. CrossRef Medline

Ayala YA, Malmierca MS (2014) Cholinergic modulation of stimulusspecific adaptation in the inferior colliculus. Paper presented at 9th FENS Forum of Neuroscience, July, Milan, Italy.

Ayala YA, Malmierca MS (2015) Modulation of auditory deviant saliency in the inferior colliculus. Paper presented at ARO MidWinter Meeting, February, Baltimore, MD.

Ayala YA, Pérez-González D, Duque D, Nelken I, Malmierca MS (2013) Frequency discrimination and stimulus deviance in the inferior colliculus and cochlear nucleus. Front Neural Circuits 6:119. CrossRef.

Ayala YA, Udeh A, Dutta K, Bishop D, Malmierca MS, Oliver DL (2015) Differences in the strength of cortical and brainstem inputs to SSA and non-SSA neurons in the inferior colliculus. Sci Rep 5:10383. CrossRef

Bajo VM, Leach ND, Cordery PM, Nodal FR, King AJ (2014) The cholinergic basal forebrain in the ferret and its inputs to the auditory cortex. Eur J Neurosci 40:2922-2940. CrossRef Medline

Bakin JS, Weinberger NM (1996) Induction of a physiological memory in the cerebral cortex by stimulation of the nucleus basalis. Proc Natl Acad Sci U S A 93:11219-11224. CrossRef Medline

Clarke PB, Pert CB, Pert A (1984) Autoradiographic distribution of nicotine receptors in rat brain. Brain Res 323:390-395. CrossRef Medline

Clarke PB, Schwartz RD, Paul SM, Pert CB, Pert A (1985) Nicotinic binding in rat brain: autoradiographic comparison of $[3 \mathrm{H}]$ acetylcholine, $[3 \mathrm{H}] \mathrm{ni}-$ cotine, and [125I]-alpha-bungarotoxin. J Neurosci 5:1307-1315. Medline

Cole AE, Nicoll RA (1984) The pharmacology of cholinergic excitatory responses in hippocampal pyramidal cells. Brain Res 305:283-290. CrossRef Medline

Cortés R, Palacios JM (1986) Muscarinic cholinergic receptor subtypes in the rat brain. I. Quantitative autoradiographic studies. Brain Res 362:227238. CrossRef Medline

Duque D, Malmierca MS (2014) Stimulus-specific adaptation in the inferior colliculus of the mouse: anesthesia and spontaneous activity effects. 
Brain Struct Funct. Advance online publication. Retrieved August 13, 2014. doi:10.1007/s00429-014-0862-1. CrossRef

Duque D, Pérez-González D, Ayala YA, Palmer AR, Malmierca MS (2012) Topographic distribution, frequency, and intensity dependence of stimulus-specific adaptation in the inferior colliculus of the rat. J Neurosci 32:17762-17774. CrossRef Medline

Duque D, Malmierca MS, Caspary DM (2014) Modulation of stimulusspecific adaptation by $\mathrm{GABA}(\mathrm{A})$ receptor activation or blockade in the medial geniculate body of the anaesthetized rat. J Physiol 592:729-743. CrossRef Medline

Edeline JM (2012) Beyond traditional approaches to understanding the functional role of neuromodulators in sensory cortices. Front Behav Neurosci 6:45. CrossRef

Edeline JM, Hars B, Maho C, Hennevin E (1994) Transient and prolonged facilitation of tone-evoked responses induced by basal forebrain stimulations in the rat auditory cortex. Exp Brain Res 97:373-386. Medline

Escera C, Malmierca MS (2014) The auditory novelty system: an attempt to integrate human and animal research. Psychophysiology 51:111-123. CrossRef Medline

Farley GR, Morley BJ, Javel E, Gorga MP (1983) Single-unit responses to cholinergic agents in the rat inferior colliculus. Hear Res 11:73-91. CrossRef Medline

Faure PA, Fremouw T, Casseday JH, Covey E (2003) Temporal masking reveals properties of sound-evoked inhibition in duration-tuned neurons of the inferior colliculus. J Neurosci 23:3052-3065. Medline

Fritz J, Shamma S, Elhilali M, Klein D (2003) Rapid task-related plasticity of spectrotemporal receptive fields in primary auditory cortex. Nat Neurosci 6:1216-1223. CrossRef Medline

Fritz J, Elhilali M, Shamma S (2005) Active listening: task-dependent plasticity of spectrotemporal receptive fields in primary auditory cortex. Hear Res 206:159-176. CrossRef Medline

Fritz JB, Elhilali M, Shamma SA (2007a) Adaptive changes in cortical receptive fields induced by attention to complex sounds. J Neurophysiol 98: 2337-2346. CrossRef Medline

Fritz JB, Elhilali M, David SV, Shamma SA (2007b) Does attention play a role in dynamic receptive field adaptation to changing acoustic salience in A1? Hear Res 229:186-203. CrossRef Medline

Froemke RC (2015) Plasticity of cortical excitatory-inhibitory balance. Annu Rev Neurosci 38:195-219. CrossRef Medline

Froemke RC, Merzenich MM, Schreiner CE (2007) A synaptic memory trace for cortical receptive field plasticity. Nature 450:425-429. CrossRef Medline

Froemke RC, Carcea I, Barker AJ, Yuan K, Seybold BA, Martins AR, Zaika N, Bernstein H, Wachs M, Levis PA, Polley DB, Merzenich MM, Schreiner CE (2013) Long-term modification of cortical synapses improves sensory perception. Nat Neurosci 16:79-88. Medline

Grupe M, Grunnet M, Laursen B, Bastlund JF (2014) Neuropharmacological modulation of the P3-like event-related potential in a rat two-tone auditory discrimination task with modafinil and NS9283, a positive allosteric modulator of alpha4beta2 nAChRs. Neuropharmacology 79:444455. CrossRef Medline

Habbicht H, Vater M (1996) A microiontophoretic study of acetylcholine effects in the inferior colliculus of horseshoe bats: implications for a modulatory role. Brain Res 724:169-179. CrossRef Medline

Harris KD, Thiele A (2011) Cortical state and attention. Nat Rev Neurosci 12:509-523. CrossRef Medline

Hasselmo ME, McGaughy J (2004) High acetylcholine levels set circuit dynamics for attention and encoding and low acetylcholine levels set dynamics for consolidation. Prog Brain Res 145:207-231. CrossRef Medline

Hedrick T, Waters J (2015) Acetylcholine excites neocortical pyramidal neurons via nicotinic receptors. J Neurophysiol 113:2195-2209. CrossRef Medline

Hernandez O, Espinosa N, Pérez-GonzálezD, Malmierca MS (2005) The inferior colliculus of the rat: a quantitative analysis of monaural frequency response areas. Neuroscience 132:203-217. CrossRef Medline

Hsieh CY, Cruikshank SJ, Metherate R (2000) Differential modulation of auditory thalamocortical and intracortical synaptic transmission by cholinergic agonist. Brain Res 880:51-64. CrossRef Medline

Izquierdo MA, Gutiérrez-Conde PM, Merchán MA, Malmierca MS (2008) Non-plastic reorganization of frequency coding in the inferior colliculus of the rat following noise-induced hearing loss. Neuroscience 154:355369. CrossRef Medline
Jääskeläinen IP, Ahveninen J, Belliveau JW, Raij T, Sams M (2007) Shortterm plasticity in auditory cognition. Trends Neurosci 30:653-661. CrossRef Medline

Ji W, Gao E, Suga N (2001) Effects of acetylcholine and atropine on plasticity of central auditory neurons caused by conditioning in bats. J Neurophysiol 86:211-225. Medline

Kametani H, Kawamura H (1990) Alterations in acetylcholine release in the rat hippocampus during sleep-wakefulness detected by intracerebral dialysis. Life Sci 47:421-426. CrossRef Medline

Kelly JB, Caspary DM (2005) Pharmacology of the inferior colliculus. In: The inferior colliculus (Winer JA, Schreiner CE, eds), pp 248-281. New York: Springer.

Kilgard MP, Merzenich MM (2002) Order-sensitive plasticity in adult primary auditory cortex. Proc Natl Acad Sci U S A 99:3205-3209. CrossRef Medline

Klein C, von der Behrens W, Gaese BH (2014) Stimulus-specific adaptation in field potentials and neuronal responses to frequency-modulated tones in the primary auditory cortex. Brain Topogr 27:599-610. CrossRef Medline

Knott V, Impey D, Philippe T, Smith D, Choueiry J, de la Salle S, Dort H (2014) Modulation of auditory deviance detection by acute nicotine is baseline and deviant dependent in healthy nonsmokers: a mismatch negativity study. Hum Psychopharmacol 29:446-458. CrossRef Medline

Krause M, Pedarzani P (2000) A protein phosphatase is involved in the cholinergic suppression of the $\mathrm{Ca}(2+)$-activated $\mathrm{K}(+)$ current sI(AHP) in hippocampal pyramidal neurons. Neuropharmacology 39:1274-1283. CrossRef Medline

Krnjević K (2004) Synaptic mechanisms modulated by acetylcholine in cerebral cortex. Prog Brain Res 145:81-93. Medline

Liang K, Poytress BS, Weinberger NM, Metherate R (2008) Nicotinic modulation of tone-evoked responses in auditory cortex reflects the strength of prior auditory learning. Neurobiol Learn Mem 90:138-146. CrossRef Medline

Loftus WC, Malmierca MS, Bishop DC, Oliver DL (2008) The cytoarchitecture of the inferior colliculus revisited: a common organization of the lateral cortex in rat and cat. Neuroscience 154:196-205. CrossRef Medline

Ma X, Suga N (2005) Long-term cortical plasticity evoked by electric stimulation and acetylcholine applied to the auditory cortex. Proc Natl Acad Sci U S A 102:9335-9340. CrossRef Medline

Malmierca MS, Hernández O, Falconi A, Lopez-Poveda EA, Merchán M, Rees A (2003) The commissure of the inferior colliculus shapes frequency response areas in rat: an in vivo study using reversible blockade with microinjection of kynurenic acid. Exp Brain Res 153:522-529. CrossRef Medline

Malmierca MS, Hernández O, Rees A (2005) Intercollicular commissural projections modulate neuronal responses in the inferior colliculus. Eur J Neurosci 21:2701-2710. CrossRef Medline

Malmierca MS, Izquierdo MA, Cristaudo S, Hernández O, Pérez-González D, Covey E, Oliver DL (2008) A discontinuous tonotopic organization in the inferior colliculus of the rat. J Neurosci 28:4767-4776. CrossRef Medline

Malmierca MS, Cristaudo S, Pérez-González D, Covey E (2009) Stimulusspecific adaptation in the inferior colliculus of the anesthetized rat. J Neurosci 29:5483-5493. CrossRef Medline

Malmierca MS, Blackstad TW, Osen KK (2011) Computer-assisted 3-D reconstructions of Golgi-impregnated neurons in the cortical regions of the inferior colliculus of rat. Hear Res 274:13-26. CrossRef Medline

Malmierca MS, Sanchez-Vives MV, Escera C, Bendixen A (2014) Neuronal adaptation, novelty detection and regularity encoding in audition. Front Syst Neurosci 8:111. CrossRef

Marrosu F, Portas C, Mascia MS, Casu MA, Fà M, Giagheddu M, Imperato A, Gessa GL (1995) Microdialysis measurement of cortical and hippocampal acetylcholine release during sleep-wake cycle in freely moving cats. Brain Res 671:329-332. CrossRef Medline

Martin-Cortecero J, Nunez A (2014) Tactile response adaptation to whisker stimulation in the lemniscal somatosensory pathway of rats. Brain Res 1591:27-37. CrossRef

McCormick DA (1993) Actions of acetylcholine in the cerebral cortex and thalamus and implications for function. Prog Brain Res 98:303-308. CrossRef Medline

McCormick DA, Prince DA (1986) Acetylcholine induces burst firing in 
thalamic reticular neurones by activating a potassium conductance. Nature 319:402-405. CrossRef Medline

Merrill EG, Ainsworth A (1972) Glass-coated platinum-plated tungsten microelectrodes. Med Biol Eng 10:662-672. CrossRef Medline

Metherate R (2004) Nicotinic acetylcholine receptors in sensory cortex. Learn Mem 11:50-59. CrossRef Medline

Metherate R (2011) Functional connectivity and cholinergic modulation in auditory cortex. Neurosci Biobehav Rev 35:2058-2063. CrossRef Medline

Metherate R, Ashe JH (1993) Nucleus basalis stimulation facilitates thalamocortical synaptic transmission in the rat auditory cortex. Synapse 14:132-143. CrossRef Medline

Metherate R, Hsieh CY (2003) Regulation of glutamate synapses by nicotinic acetylcholine receptors in auditory cortex. Neurobiol Learn Mem 80:285-290. CrossRef Medline

Metherate R, Weinberger NM (1989) Acetylcholine produces stimulusspecific receptive field alterations in cat auditory cortex. Brain Res 480: 372-377. CrossRef Medline

Metherate R, Weinberger NM (1990) Cholinergic modulation of responses to single tones produces tone-specific receptive field alterations in cat auditory cortex. Synapse 6:133-145. CrossRef Medline

Metherate R, Cox CL, Ashe JH (1992) Cellular bases of neocortical activation: modulation of neural oscillations by the nucleus basalis and endogenous acetylcholine. J Neurosci 12:4701-4711. Medline

Moran RJ, Campo P, Symmonds M, Stephan KE, Dolan RJ, Friston KJ (2013) Free energy, precision and learning: the role of cholinergic neuromodulation. J Neurosci 33:8227-8236. CrossRef Medline

Morley BJ, Kemp GE (1981) Characterization of a putative nicotinic acetylcholine receptor in mammalian brain. Brain Res 228:81-104. Medline

Motts SD, Schofield BR (2009) Sources of cholinergic input to the inferior colliculus. Neuroscience 160:103-114. CrossRef Medline

Näätänen R (1992) Attention and brain function. Hillsdale, NJ: Lawrence Erlbaum.

Nelken I (2014) Stimulus-specific adaptation and deviance detection in the auditory system: experiments and models. Biol Cybern 108:655-663. CrossRef Medline

Nelken I, Ulanovsky N (2007) Mismatch negativity and stimulus-specific adaptation in animal models. J Psychophysiol 21:214-223. CrossRef

Paxinos G, Watson C (2007) The rat brain in stereotaxic coordinates, Ed 6. Burlington, MA: Academic.

Pérez-González D, Malmierca MS, Covey E (2005) Novelty detector neurons in the mammalian auditory midbrain. Eur J Neurosci 22:2879-2885. CrossRef Medline

Pérez-González D, Malmierca MS, Moore JM, Hernández O, Covey E (2006) Duration selective neurons in the inferior colliculus of the rat: topographic distribution and relation of duration sensitivity to other response properties. J Neurophysiol 95:823-836. Medline

Pérez-González D, Hernandez O, Covey E, Malmierca MS (2012) GABA(A)-mediated inhibition modulates stimulus-specific adaptation in the inferior colliculus. PLoS One 7:e34297. CrossRef

Rees A (1990) A close-field sound system for auditory neurophysiology. J Physiol 430:2.

Rees A, Sarbaz A, Malmierca MS, Le Beau FE (1997) Regularity of firing of neurons in the inferior colliculus. J Neurophysiol 77:2945-2965. Medline

Richardson BD, Hancock KE, Caspary DM (2013) Stimulus-specific adap- tation in auditory thalamus of young and aged awake rats. J Neurophysiol 110:1892-1902. CrossRef Medline

Rotter A, Birdsall NJ, Field PM, Raisman G (1979) Muscarinic receptors in the central nervous system of the rat. II. Distribution of binding of $[3 \mathrm{H}]$ propylbenzilylcholine mustard in the midbrain and hindbrain. Brain Res 180:167-183. Medline

Salgado H, Bellay T, Nichols JA, Bose M, Martinolich L, Perrotti L, Atzori M (2007) Muscarinic M2 and M1 receptors reduce GABA release by Ca2+ channel modulation through activation of PI3K/Ca2 + -independent and PLC/Ca2+ -dependent PKC. J Neurophysiol 98:952-965. CrossRef Medline

Sanchez-Vives MV, Nowak LG, McCormick DA (2000a) Membrane mechanisms underlying contrast adaptation in cat area 17 in vivo. J Neurosci 20:4267-4285. Medline

Sanchez-Vives MV, Nowak LG, McCormick DA (2000b) Cellular mechanisms of long-lasting adaptation in visual cortical neurons in vitro. J Neurosci 20:4286-4299. Medline

Sarter M, Hasselmo ME, Bruno JP, Givens B (2005) Unraveling the attentional functions of cortical cholinergic inputs: interactions between signal-driven and cognitive modulation of signal detection. Brain Res Brain Res Rev 48:98-111. CrossRef Medline

Schofield BR (2010) Projections from auditory cortex to midbrain cholinergic neurons that project to the inferior colliculus. Neuroscience 166 : 231-240. CrossRef Medline

Schofield BR, Motts SD (2009) Projections from auditory cortex to cholinergic cells in the midbrain tegmentum of guinea pigs. Brain Res Bull 80:163-170. CrossRef Medline

Schofield BR, Motts SD, Mellott JG (2011) Cholinergic cells of the pontomesencephalic tegmentum: connections with auditory structures from cochlear nucleus to cortex. Hear Res 279:85-95. CrossRef Medline

Thiele A (2013) Muscarinic signaling in the brain. Annu Rev Neurosci 36: 271-294. CrossRef Medline

Todorovic A, de Lange FP (2012) Repetition suppression and expectation suppression are dissociable in time in early auditory evoked fields. J Neurosci 32:13389-13395. CrossRef Medline

Ulanovsky N, Las L, Nelken I (2003) Processing of low-probability sounds by cortical neurons. Nat Neurosci 6:391-398. CrossRef Medline

Ulanovsky N, Las L, Farkas D, Nelken I (2004) Multiple time scales of adaptation in auditory cortex neurons. J Neurosci 24:10440-10453. CrossRef Medline

von der Behrens W, Bäuerle P, KösslM, Gaese BH (2009) Correlating stimulus-specific adaptation of cortical neurons and local field potentials in the awake rat. J Neurosci 29:13837-13849. CrossRef Medline

Watanabe T, Simada Z (1973) Pharmacological properties of cat's collicular auditory neurons. Jpn J Physiol 23:291-308. CrossRef Medline

Watkins PV, Barbour DL (2011) Level-tuned neurons in primary auditory cortex adapt differently to loud versus soft sounds. Cereb Cortex 21:178190. CrossRef Medline

Zaborszky L, van den Pol A, Gyengesi E (2012) The basal forebrain cholinergic projection system in mice. In: The mouse nervous system, Ed 1 (Watson C, Paxinos G, Puelles L, eds), pp 684-718. Amsterdam: Academic.

Zhang W, Yamada M, Gomeza J, Basile AS, Wess J (2002) Multiple muscarinic acetylcholine receptor subtypes modulate striatal dopamine release, as studied with M1-M5 muscarinic receptor knock-out mice. J Neurosci 22:6347-6352. Medline 